\title{
Phylogeny and systematics of the Proterodiplostomidae Dubois, 1936 (Digenea: Diplostomoidea) reflect the complex evolutionary history of the ancient digenean group
}

\author{
Vasyl V. Tkach (D) Tyler J. Achatz • Eric E. Pulis • Kerstin Junker • \\ Scott D. Snyder · Jeffrey A. Bell · Ali Halajian - Francisco Tiago de Vasconcelos Melo
}

Received: 27 June 2020 / Accepted: 12 July 2020/Published online: 19 August 2020

(C) Springer Nature B.V. 2020

\begin{abstract}
The Proterodiplostomidae Dubois, 1936 is a relatively small family of diplostomoidean digeneans parasitising the intestines of reptilian hosts associated with freshwater environments in tropical
\end{abstract}

This article was registered in the Official Register of Zoological Nomenclature (ZooBank) as urn:lsid:zoobank.org:pub:C7731 46C-F377-4C30-A73A-318D21119F9C. This article was published as an Online First article on the online publication date shown on this page. The article should be cited by using the doi number. This is the Version of Record.

This article is part of the Topical Collection Digenea

Electronic supplementary material The online version of this article (https://doi.org/10.1007/s11230-020-09928-2) contains supplementary material, which is available to authorized users.

V. V. Tkach $(\bowtie) \cdot$ T. J. Achatz · J. A. Bell

Department of Biology, University of North Dakota, 10 Cornell Street, Grand Forks, North Dakota 58202, USA

e-mail: vasyl.tkach@und.edu

E. E. Pulis

Department of Science and Mathematics, Northern State University, Aberdeen, South Dakota 57401, USA

K. Junker

Epidemiology, Parasites and Vectors, ARC-Onderstepoort

Veterinary Institute, Onderstepoort 0110, South Africa

S. D. Snyder

College of Science and Engineering, Idaho State

University, Pocatello, Idaho, USA and subtropical regions. The greatest diversity of proterodiplostomids is found in crocodilians, although some parasitise snakes and turtles. According to the most recent revision, the Proterodiplostomidae included 17 genera within 5 subfamilies. Despite the complex taxonomic structure of the family, availability of testable morphology-based phylogenetic hypotheses and ancient hosts, molecular phylogenetic analyses of the group were practically lacking. Herein, we use novel DNA sequence data of the nuclear lsrRNA gene and mitochondrial cox 1 gene from a broad range of proterodiplostomid taxa obtained from crocodilian, fish, and snake hosts on four continents to test the monophyly of the family and evaluate the present morphology-based classification system of the Proterodiplostomidae in comparison with the

\author{
A. Halajian \\ DSI-NRF SARChI Chair (Ecosystem Health), Department \\ of Biodiversity, University of Limpopo, \\ Private Bag X1106, Sovenga 0727, South Africa \\ F. T. de Vasconcelos Melo \\ Laboratory of Cell Biology and Helminthology "Prof. Dr. \\ Reinalda Marisa Lanfredi", Institute of Biological \\ Sciences, Federal University of Pará, Belém, \\ PA, Brazil
}


molecular phylogeny. This first detailed phylogeny for the Proterodiplostomidae challenges the current systematic framework. Combination of molecular phylogenetic data with examination of freshly collected quality specimens and re-evaluation of morphological criteria resulted in a number of systematic and nomenclatural changes along with a new phylogenybased classification of the Proterodiplostomidae. As the result of our molecular and morphological analyses: (i) the current subfamily structure of the Proterodiplostomidae is abolished; (ii) three new genera, Paraproterodiplostomum n. g., Neocrocodilicola n. g. and Proteroduboisia n. g., are described and Pseudoneodiplostomoides Yamaguti, 1954 is restored and elevated from subgenus to genus level; (iii) two new species, Paraproterodiplostomum currani n. g., n. sp. and Archaeodiplostomum overstreeti n. sp., are described from the American alligator in Mississippi, USA. Comparison of the structure of terminal ducts of the reproductive system in all proterodiplostomid genera did not support the use of these structures for differentiation among subfamilies (or major clades) within the family, although they proved to be useful for distinguishing among genera and species. Our study includes the first report of proterodiplostomids from Australia and the first evidence of a snake acting as a paratenic host for a proterodiplostomid. A key to proterodiplostomid genera is provided. Questions of proterodiplostomid-host associations parasitic in crocodilians are discussed in connection with their historical biogeography. Our molecular phylogeny of the Proterodiplostomidae closely matches the current molecular phylogeny of crocodilians. Directions for future studies of the Proterodiplostomidae are outlined.

\section{Introduction}

The Proterodiplostomidae Dubois, 1936 is a relatively small family of diplostomoidean digeneans parasitising the intestines of reptilian hosts associated with freshwater environments, mostly in the tropical and subtropical regions of the world. The greatest diversity of proterodiplostomids is found in crocodilians, although some parasitise snakes and turtles (Dubois, 1979; Niewiadomska, 2002). Members of the Proterodiplostomidae are characterised by the presence of a thin- or thick-walled tubule or pouch surrounded by glandular cells associated with the terminal ducts of their reproductive system called a paraprostate (Niewiadomska, 2002).

Dubois (1936) established the Proterodiplostomidae for diplostomids from reptiles which possessed a paraprostate. The early systems of the family proposed by Dubois $(1936,1951)$ were based on host associations and a wide range of morphological characters including size of the holdfast organ, presence or absence of papillae on the margins of the holdfast organ, distribution of vitelline follicles, and arrangement of terminal reproductive ducts. Dubois (1953) revisited the systematics of the family and separated the Proterodiplostomidae into two "super-subfamilies" based on host associations (crocodilians and chelonians vs snakes). Byrd \& Reiber (1942) and later Brooks et al. (1992) proposed systematic revisions of the Proterodiplostomidae with a stronger emphasis on the organization of the terminal ducts of the reproductive system. However, Niewiadomska (2002) in her most recent revision of the Proterodiplostomidae viewed the revision by Brooks et al. (1992) as too preliminary to be broadly adopted as a basis for the current system of the family. According to Niewiadomska (2002), the Proterodiplostomidae includes 17 genera within five subfamilies: Massoprostatinae Yamaguti, 1958 (1 genus), Ophiodiplostominae Dubois, 1936 (2 genera), Polycotylinae Monticelli, 1888 (8 genera), Proalarioidinae Sudarikov, 1960 (1 genus) and Proterodiplostominae Dubois, 1936 (5 genera).

Members of the family are distributed on different continents and occur in some of the most ancient groups of amniotic tetrapods, thus representing an extremely interesting model for phylogenetic and phylogeographic studies. However, the current systematics and taxonomy of the Proterodiplostomidae as well as all existing phylogenetic reconstructions of the group (e.g. Brooks, 1979; Brooks \& O'Grady, 1989) are morphology-based. The lack of a molecular phylogenetic assessment of the group has prevented us from addressing such intriguing questions as the patterns of their current and past geographical distribution, host-associations, or the monophyly of recognised taxa. Likewise, the true interrelationships among the genera within the Proterodiplostomidae remain completely unknown. In fact, the position of the Proterodiplostomidae among other digeneans was tested based only on DNA sequences obtained from metacercariae of only two species belonging to two of 
the 17 currently accepted genera, with only weak support (Hernández-Mena et al., 2017; Queiroz et al., 2020). Molecular data are also important as an independent set of characters that may help to assess the relative taxonomic value of morphological characters traditionally used to outline and differentiate among proterodiplostomid taxa including peculiarities of organization of the reproductive system and structure of the holdfast organ.

While significant progress has been recently achieved in the molecular phylogenetics and systematics of the Diplostomoidea Poirier, 1886 and its major constituent lineages (e.g. Blasco-Costa \& Locke, 2017; Hernández-Mena et al., 2017; Locke et al., 2018; Achatz et al., 2019b, c, d; Queiroz et al., 2020), the Proterodiplostomidae remains one of the only diplostomoidean families to receive very little attention in molecular phylogenetic studies. This can be partly explained by the logistic challenges of obtaining fresh material from hosts that are often protected and difficult to collect.

This study is focused on the proterodiplostomids of crocodilians. Based on the available descriptions, taxonomic revisions, and checklists (Dubois, 1979; Catto \& Amato, 1994; Tellez, 2014), there are five named species of proterodiplostomids belonging to four genera reported from crocodilians in the Nearctic: Archaeodiplostomum acetabulata (Byrd \& Reiber, 1942); Crocodilicola pseudostoma Willemoes-Suhm, 1870; Polycotyle ornata Willemoes-Suhm, 1870; Pseudocrocodilicola americaniense Byrd \& Reiber, 1942; and Pseudocrocodilicola georgiana Byrd \& Reiber, 1942. There are 11 species of proterodiplostomids belonging to seven genera known from crocodilians in the Neotropics: Cr. pseudostoma; Cystodiplostomum hollyi Dubois, 1936; Herpetodiplostomum caimancola (Dollfus, 1935); Mesodiplostomum gladiolum Dubois, 1936; Paradiplostomum abbreviatum (Brandes, 1888); Prolecithodiplostomum constrictum Dubois, 1936; Proterodiplostomum breve Catto \& Amato, 1994; Proterodiplostomum globulare Catto \& Amato, 1994; Proterodiplostomum longum (Brandes, 1888); Proterodiplostomum medusae (Dubois, 1936); Proterodiplostomum tumidulum Dubois, 1936; and Pseudoneodiplostomum groschafti Moravec, 2001. In the Afrotropics, there are only two species of proterodiplostomids belonging to a single genus that parasitise crocodilians: Pseudoneodiplostomum bifurcatum (Wedl, 1861) and Pseudoneodiplostomum thomasi (Dollfus, 1935). A further three species of proterodiplostomids parasitise crocodilians in the Indomalayan region, each belonging to a separate genus: Capsulodiplostomum crocodilinum Dwivedi, 1966; Herpetodiplostomum gavialis (Narain, 1930); and Pseudoneodiplostomum siamense (Poirier, 1886). No proterodiplostomids have been previously reported from crocodilians in Australia.

In this study, we collected numerous specimens of multiple proterodiplostomid species from four species of crocodilian hosts in Australia, Brazil, South Africa, and the USA, in addition to specimens of Heterodiplostomum lanceolatum Dubois, 1936 from a frog and a snake from Brazil. We use partial sequences of the nuclear large ribosomal subunit RNA gene (28S) and the mitochondrial cytochrome $c$ oxidase subunit 1 ( $\operatorname{cox} 1)$ gene to analyse the phylogenetic position of the Proterodiplostomidae, test its monophyly, and examine the interrelationships among its constituent taxa. In addition, we erect three new genera and describe two new species of proterodiplostomids from the American alligator Alligator mississippiensis (Daudin), re-evaluate some current proterodiplostomid genera, and provide an updated key for the identification of proterodiplostomids to genus level.

\section{Materials and methods}

Several of the genera discussed in the present work have very similar spellings, which prevents the standard use of the first or first and second letters for abbreviation. As such, we use the following abbreviations to refer to genera: Al., Alligator Cuvier; Ar., Archaeodiplostomum Dubois, 1944; Co., Crocodylus Laurenti; Cr., Crocodilicola Poche, 1926; Cy., Cystodiplostomum Dubois, 1936; He., Heterodiplostomum Dubois, 1936; Me., Mesodiplostomum Dubois, 1936; Ne., Neocrocodilicola n. g.; Pa., Paradiplostomum La Rue, 1926; Pe., Pseudoneodiplostomum Dubois, 1936; Po., Polycotyle Willemoes-Suhm, 1870; Pp., Paraproterodiplostomum n. g.; Pr., Proterodiplostomum Dubois, 1936; Ps., Pseudocrocodilicola Byrd \& Reiber, 1942; Pt., Proteroduboisia n. g.; Pu., Pseudoneodiplostomoides Yamaguti, 1954. 


\section{Morphological data}

Adult or immature specimens belonging to the Proterodiplostomidae were collected from the intestines of the following hosts: Al. mississippiensis from the Pascagoula Wildlife Management Area, Jackson Co., Mississippi, USA $\left(30^{\circ} 37^{\prime} 07.2^{\prime \prime} \mathrm{N}\right.$, $88^{\circ} 37^{\prime} 08.9^{\prime \prime} \mathrm{W}$ ), between 2004 and 2015; yacare caiman Caiman yacare Daudin, yellow-bellied liophis snake Erythrolamprus poecilogyrus (Wied-Neuwied) and Cei's white-lipped frog Leptodactylus chaquensis Cei from Fazenda Retiro Novo, Pantanal, Municipality of Nossa Senhora do Livramento, Mato Grosso State, Brazil, in 2016 and 2019; spectacled caiman Caiman crocodilus Linnaeus from the vicinity near Iquitos, Peru in 2016 (kindly provided by Dr Stephen Bullard, Auburn University); Australian freshwater crocodile Crocodylus johnstoni Krefft from Daly River near Oolloo Crossing, Northern Territory, Australia $\left(14^{\circ} 00.31^{\prime} \mathrm{S}, 131^{\circ} 14.46^{\prime} \mathrm{E}\right)$ in 2006 ; and Nile crocodile Crocodylus niloticus Laurenti from the Olifants River, Limpopo Province $\left(24^{\circ} 3^{\prime} \mathrm{S}, 31^{\circ} 13^{\prime} \mathrm{E}\right)$ and Crocodile River, Mpumalanga Province, South Africa $\left(25^{\circ} 27^{\prime} \mathrm{S}, 31^{\circ} 58^{\prime} \mathrm{E}\right)$ in 2010 and Flag Boshielo Dam, Marble Hall, Limpopo Province $\left(24^{\circ} 51^{\prime} 00.5^{\prime \prime} \mathrm{S}\right.$, $29^{\circ} 22^{\prime} 55.8^{\prime \prime} \mathrm{E}$ ), South Africa in 2016. In addition, a proterodiplostomid metacercaria was collected from the mesenteries of the Mississippi green water snake Nerodia cyclopion (Duméril, Bibron \& Duméril) and an immature proterodiplostomid was obtained from the intestine of the banded water snake Nerodia fasciata (Linnaeus) from the Pascagoula Wildlife Management Area, Jackson Co., Mississippi, USA $\left(30^{\circ} 38^{\prime} 16.5^{\prime \prime} \mathrm{N}, \quad 88^{\circ} 36^{\prime} 35.9^{\prime \prime} \mathrm{W}\right)$ in $2011-2012$ (Table 1). In most cases, live digeneans removed from the hosts were briefly rinsed in saline, killed with hot water, and fixed in $80 \%$ ethanol. Live digeneans from Co. niloticus were killed with hot saline, fixed in $10 \%$ formalin, and transferred to $70 \%$ ethanol. Dead digeneans from the frozen carcass of the Nile crocodile from Flag Boshielo Dam were immediately fixed in $80 \%$ ethanol. Specimens for light microscopy were stained with aqueous alum carmine according to Lutz et al. (2017). Specimens were identified and measured using an Olympus BX51 compound microscope (Tokyo, Japan), equipped with differential interference contrast optics, a digital camera and Rincon measurement software (Imaging Planet, Goleta, California, USA). Drawings were made under a Leica DMC 4500 microscope (Buffalo Grove, Illinois, USA) with the aid of a drawing tube. All measurements given in the text and tables are in micrometres.

Different authors referred to the two distinct body parts in diplostomoideans as prosoma/opisthosoma, or forebody/hindbody, or anterior/posterior segments. The latest revision by Niewiadomska (2002) in the "Keys to the Trematoda" used the terms forebody and hindbody for these body parts whereas a different meaning was given to the same terms in chapters on all other distome digeneans, which was somewhat confusing. To avoid confusion, we use the terms prosoma and opisthosoma (e.g. Achatz et al., $2019 \mathrm{a}, \mathrm{c})$ to reflect the fact that these parts of the body in diplostomoideans are not segments (e.g. unlike segments or proglottides in cestodes) and the terms forebody and hindbody are universally used to designate the parts of body posterior and anterior to the ventral sucker in distome digeneans. Our use of this terminology is also consistent with its use in similar situations among other invertebrates, e.g. arachnids.

Historically, the muscular structure surrounding one or more terminal parts of the reproductive system (e.g. the paraprostate, ejaculatory duct, hermaphroditic duct, metraterm or a combination of the above) in some proterodiplostomids was called a secondary muscular pouch, a muscular sac, a muscular bulb or a capsule. These terms were used without a proper definition or distinct separation between them. Since all these terms refer to structures with a somewhat similar organisation and topology, differing only in size or their level of development, we use the unified term "muscular pouch" for these structures.

Type- and voucher specimens are deposited in the collection of the Harold W. Manter Laboratory (HWML), University of Nebraska State Museum, Lincoln, NE, USA, or the Museu Paraense Emílio Goeldi (MPEG), Belém, Pará State, Brazil. For comparative purposes we examined specimens of $\mathrm{Cr}$. pseudostoma from Crocodylus moreletii Duméril \& Bibron collected in Mexico and deposited by Vernon Thatcher in the HWML (accession number 21420).

\section{Molecular data}

Genomic DNA was extracted from single specimens of worms according to the protocol described by 


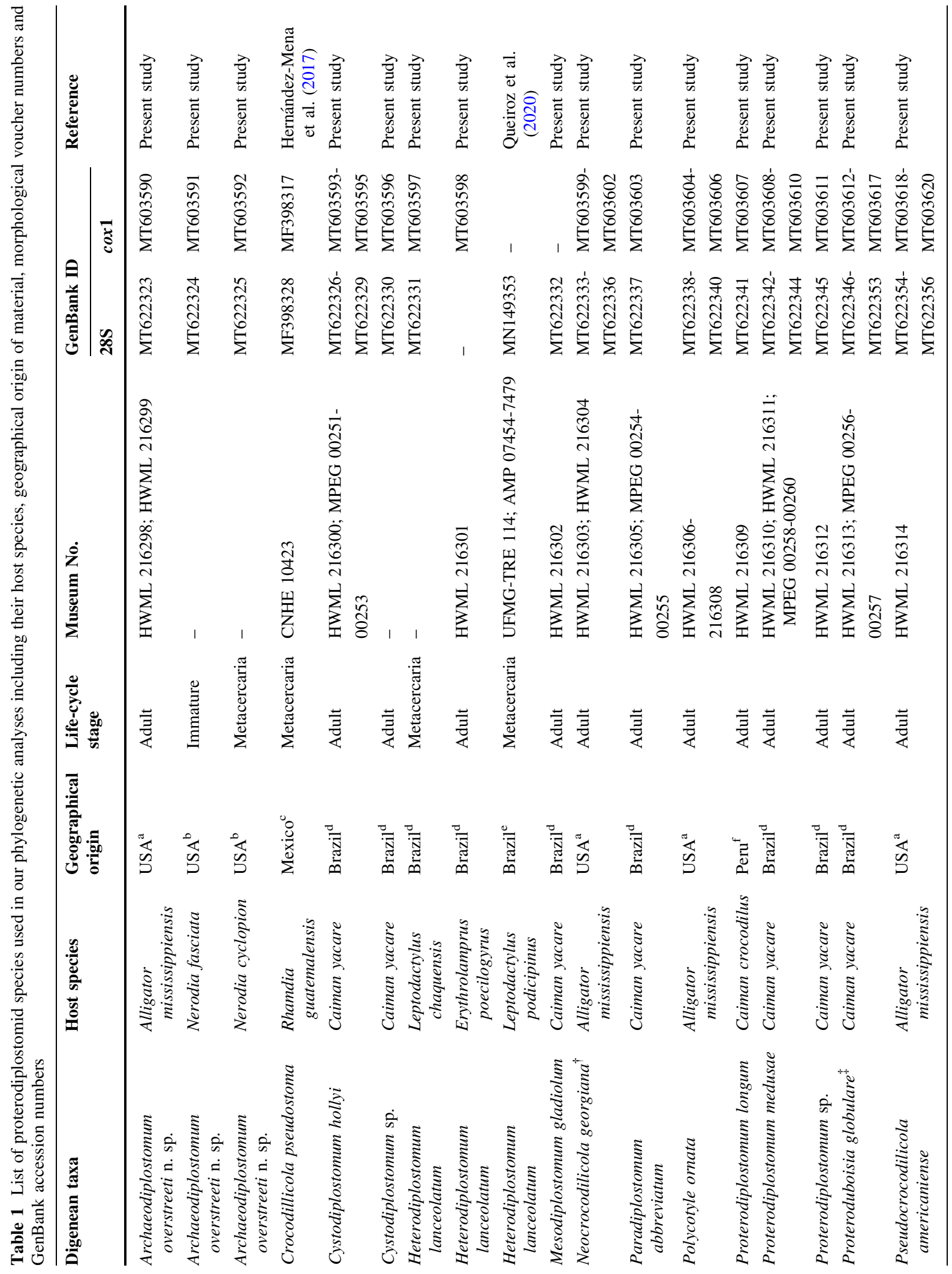




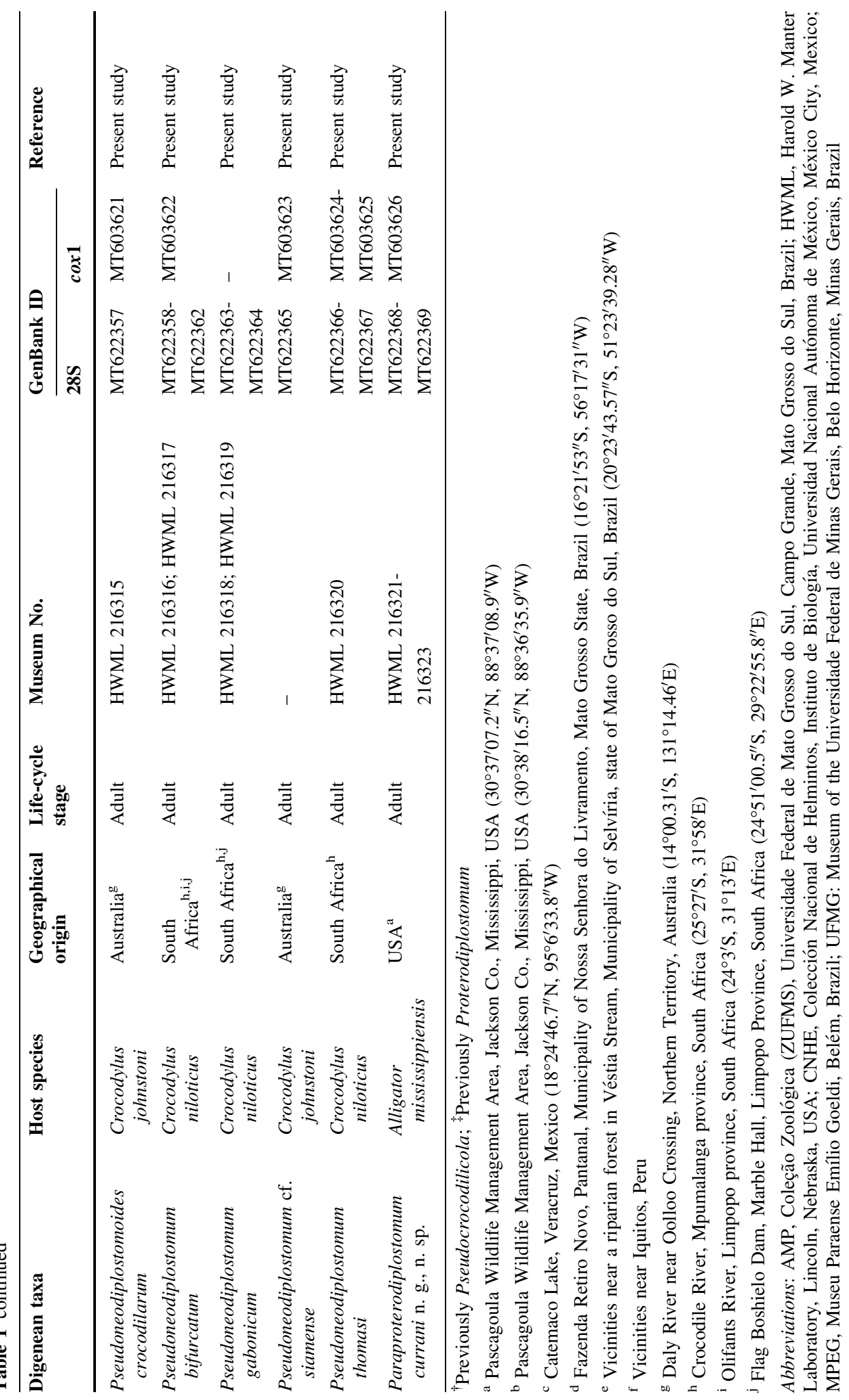


Tkach \& Pawlowski (1999) or using a ZR Genomic DNA $^{\mathrm{TM}}$ Tissue Micro Prep kit (Zymo Research, Irvine, California, USA) following the manufacturer's protocol. An approximately 1,300-bp long fragment at the $5^{\prime}$-end of the $28 \mathrm{~S}$ gene was amplified by polymerase chain reactions (PCR) on a $\mathrm{T} 100^{\mathrm{TM}}$ thermal cycler (Bio-Rad, Hercules, California, USA) using the forward primer digL2 ( $5^{\prime}$-AAG CAT ATC ACT AAG CGG- $\left.3^{\prime}\right)$ and the reverse primer $1500 \mathrm{R}\left(5^{\prime}\right.$-GCT ATC CTG AGG GAA ACT TCG-3') (Tkach et al., 2003). A fragment of the cox 1 gene was amplified using the forward primers Plat-diploCOX1F (5'-CGT TTR AAT TAT ACG GAT CC-3') and Cox1_Schist_5' (5'-TCT TTR GAT CAT AAG CG-3') and the reverse primers Plat-diploCOX1R (5'-AGC ATA GTA ATM GCA GCA GC- $\left.3^{\prime}\right)$, acox650R (5'-CCA AAA AAC CAA AAC ATA TGC TG-3') and JB5 (5'-AGC ACC TAA ACT TAA AAC ATA ATG AAA ATG-3') (Lockyer et al., 2003; Derycke et al., 2005; Moszczynska et al., 2009; Kudlai et al., 2015). PCRs were performed in a total volume of $25 \mu \mathrm{l}$ using One-Taq quick load PCR mix from New England Biolabs (Ipswich, Massachusetts, USA) or $50 \mu 1$ using GoTaq G2 DNA Polymerase from Promega (Madison, Wisconsin, USA) according to the manufacturer's instructions and using an annealing temperature of $53{ }^{\circ} \mathrm{C}$ for nuclear rRNA amplifications and $45{ }^{\circ} \mathrm{C}$ for $\operatorname{cox} 1$ amplifications.

PCR products were purified using ExoSAP-IT PCR clean-up enzymatic kit from Affymetrix (Santa Clara, California, USA) following the manufacturer's protocol. PCR products were cycle-sequenced directly using MCLab BrightDye ${ }^{\circledR}$ terminator chemistry (Molecular Cloning Laboratories, San Francisco, California, USA), cleaned using MCLab BigDye magnetic beads and run on an ABI 3130 automated capillary sequencer (Thermo Fisher Scientific, Waltham, Massachusetts, USA).

PCR primers along with the $28 \mathrm{~S}$ internal forward primer DPL600F (5'-CGG AGT GGT CAC CAC GAC CG- $\left.3^{\prime}\right)$ and reverse primer DPL700R (5'-CAG CTG ATT ACA CCC AAA G-3') and $\operatorname{cox} 1$ internal forward primer BS_CO1_IntF (5'-ATT AAC CCT CAC TAA ATG ATT TTT TTY TTT YTR ATG CC$\left.3^{\prime}\right)$ and reverse primer (5'-TAA TAC GAC TCA CTA TAA AAA AAA MAM AGA AGA RAA MAC MGT AGT AAT- $3^{\prime}$ ) were used for sequencing reactions (Achatz et al., 2019a, d). Contiguous sequences were assembled using Sequencher version 4.2 software
(GeneCodes Corp., Ann Arbor, Michigan, USA). Newly obtained sequences are deposited in the GenBank database (Table 1).

Sequences were initially aligned using ClustalW implemented in MEGA7 software (Kumar et al., 2016). The position of proterodiplostomid genera among other diplostomoidean families was studied using an alignment that included newly obtained $28 \mathrm{~S}$ sequences of 12 proterodiplostomid taxa, previously published sequences of Cr. pseudostoma, He. lanceolatum, 17 representatives of the Diplostomidae Poirier, 1886, and 13 taxa of the Strigeidae Railliet, 1919. Suchocyathocotyle crocodili (Yamaguti, 1954) was used as an outgroup based on the phylogeny published by Achatz et al. (2019d).

Interrelationships within the Proterodiplostomidae were studied using a second alignment of $28 \mathrm{~S}$ sequences along with an alignment of cox 1 sequences. Alaria mustelae Bosma, 1931 was as the outgroup in both alignments based on the previously published phylogenies and the results of our phylogeny based on the first $28 \mathrm{~S}$ alignment (see above). The second alignment of the Proterodiplostomidae included newly obtained sequences of 19 proterodiplostomid species and previously published sequences of Cr. pseudostoma and He. lanceolatum. The cox 1 alignment included newly obtained sequences of 18 proterodiplostomid species and a single previously published sequence of Cr. pseudostoma. Despite all our efforts, we were unable to successfully amplify and sequence cox 1 for Me. gladiolum and Pseudoneodiplostomum gabonicum Dubois, 1948.

Phylogenetic analyses were conducted using Bayesian inference (BI) as implemented in MrBayes Ver. 3.2.6 software (Ronquist \& Huelsenbeck, 2003). The general time-reversible model with estimates of invariant sites and gamma-distributed among-site variation $(\mathrm{GTR}+\mathrm{I}+\mathrm{G})$ was identified as the bestfitting nucleotide substitution model for all datasets using MEGA7. Bayesian inference analysis for both 28S datasets were performed using MrBayes software as follows: Markov chain Monte Carlo (MCMC) chains were run for 6,000,000 generations with sample frequency set at 1,000. Bayesian inference analysis for the cox 1 dataset was performed using MrBayes software as follows: Markov chain Monte Carlo (MCMC) chains were run for 3,000,000 generations with sample frequency set at 1,000. Log-likelihood scores were plotted and only the final $75 \%$ of trees 


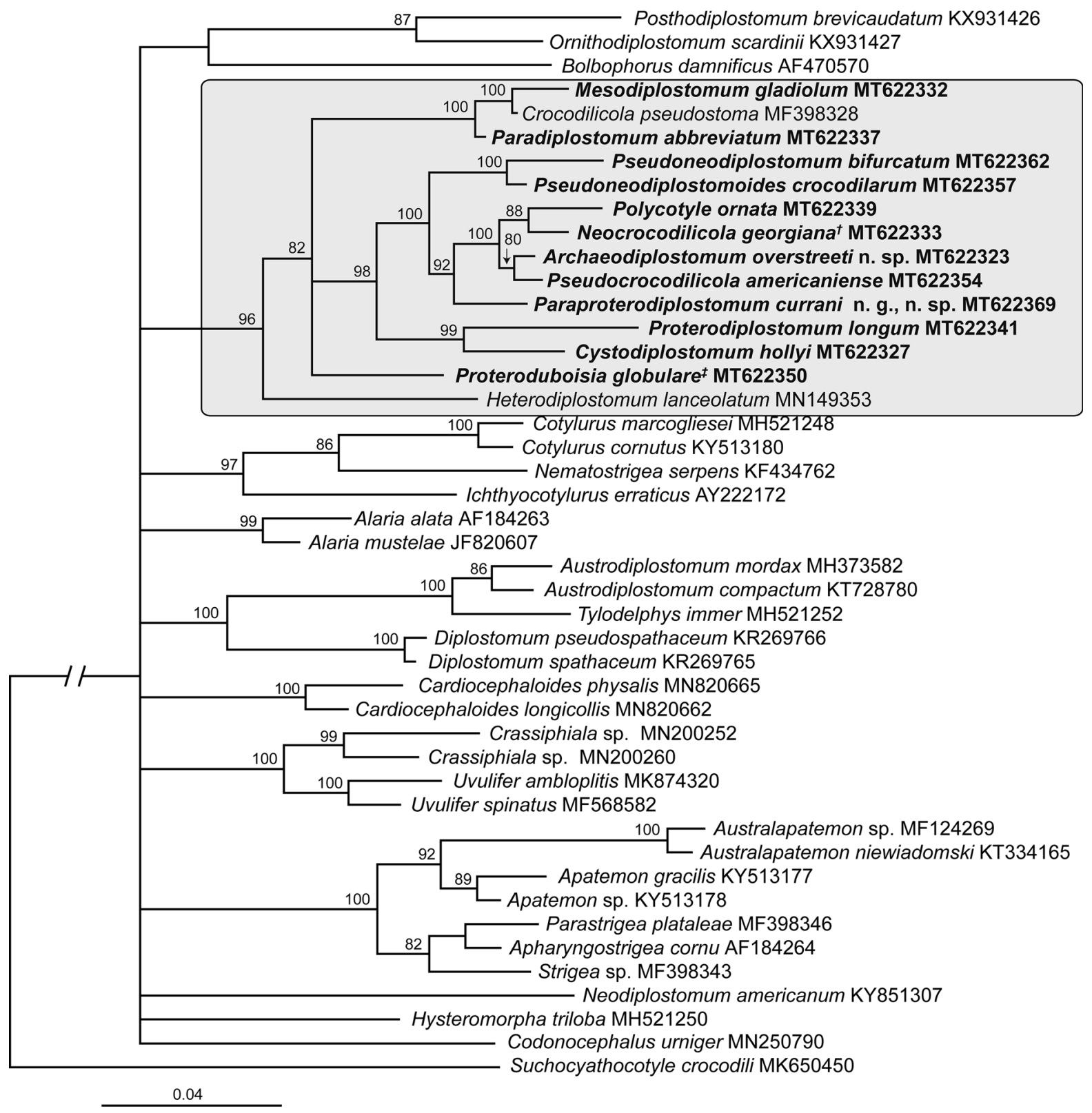

Fig. 1 Phylogenetic relationships between the taxa of the Diplostomoidea resulting from Bayesian inference (BI) analysis based on the partial sequences of the nuclear 28S rRNA gene. Bayesian inference posterior probability values are shown above branches; support values lower than $0.80(80 \%)$ are not shown. GenBank accession numbers are provided after the names of species. The scale-bar indicates the number of substitutions per site. Newly generated sequences are highlighted in bold; shaded rectangle indicates the taxa belonging to the Proterodiplostomidae. $\uparrow$ Previously Pseudocrocodilicola; $\$$ Previously Proterodiplostomum

were used to produce the consensus trees. The number of generations for each analysis was considered sufficient as the standard deviation stabilised below 0.01 in all analyses. Pairwise sequence comparisons were done for sequences included in both $28 \mathrm{~S}$ and $\operatorname{cox} 1$ analyses with assistance of MEGA7 software.
To comply with the regulations set out in Article 8.5 of the amended 2012 version of the International Code of Zoological Nomenclature (ICZN, 2012), details of all new taxa have been submitted to ZooBank. For each new taxon, the Life Science Identifier (LSID) is reported in the taxonomic summary. 


\section{Results}

\section{Molecular phylogeny}

Upon trimming to the length of the shortest sequence obtained from GenBank, the first 28S alignment, which included proterodiplostomids along with members of other diplostomoidean families, was 1,104 bp long; 19 nucleotide positions were excluded due to ambiguous homology. In the phylogenetic tree resulting from the BI analysis, all members of the Proterodiplostomidae formed a strongly supported (96\%) monophyletic clade (Fig. 1). This clade was overall very well resolved with high support for almost all topologies. Heterodiplostomum lanceolatum formed a sister branch to all other members of the Proterodiplostomidae, although the latter cluster had a somewhat low support (82\%). A more detailed analysis of the interrelationships within the Proterodiplostomidae is provided below. Similar to other recent molecular phylogenies of the Diplostomoidea, the currently accepted Diplostomidae and Strigeidae were non-monophyletic. This was demonstrated and discussed in several recent studies (e. g. Blasco-Costa \& Locke, 2017; Hernández-Mena et al., 2017; Locke et al., 2018; Achatz et al., 2019b, c, d, 2020; Queiroz et al., 2019); therefore, we do not describe details here.

The second $28 \mathrm{~S}$ alignment containing only proterodiplostomids was $1,102 \mathrm{bp}$ long after trimming to the length of the shortest sequence; 15 nucleotide positions were excluded due to ambiguous homology and indels. The phylogenetic tree resulting from the BI analysis of the second $28 \mathrm{~S}$ alignment was wellresolved, except for a basal polytomy which included four strongly supported clades (Fig. 2).

The highly supported (99\%) clade I contained the majority of proterodiplostomid taxa and was divided into two major sub-clades. The first major sub-clade of clade I included all Nearctic species collected from

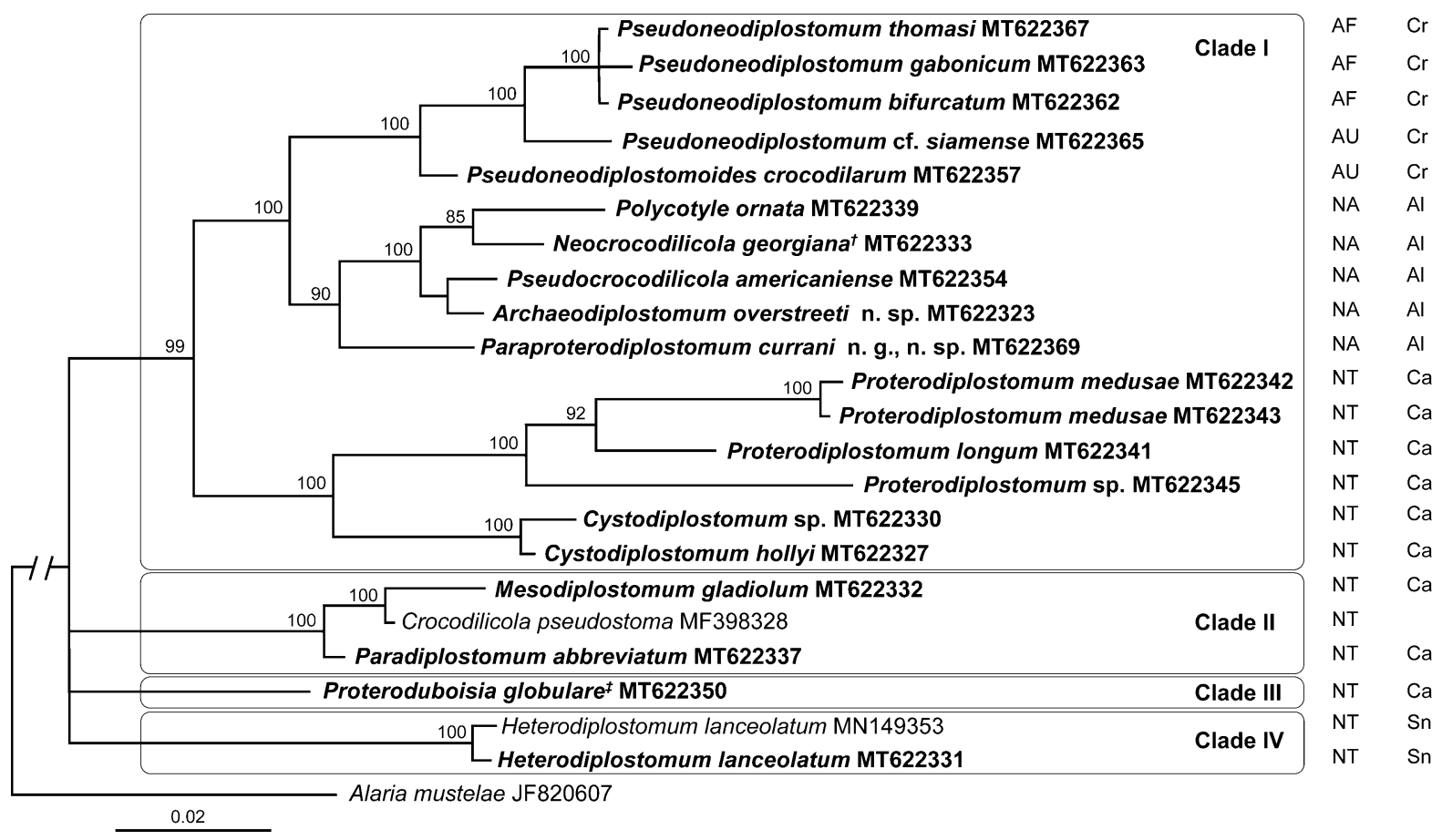

Fig. 2 Phylogenetic relationships between the taxa of the Proterodiplostomidae resulting from Bayesian inference (BI) analysis based on the partial sequences of the nuclear 28S rRNA gene. Bayesian inference posterior probability values are shown above branches; support values lower than $0.80(80 \%)$ are not shown. The scale-bar indicates the number of substitutions per site. Newly generated sequences are highlighted in bold; rectangles indicate the four major monophyletic clades. GenBank accession numbers are provided after the names of species. Biogeographical realms and definitive host groups are indicated in two columns on the right. Abbreviations for biogeographical realms: AF, Afrotropical realm; AU, Australasian realm; NA, Nearctic realm; NT, Neotropical realm. Abbreviations for definitive host groups: Cr, true crocodiles (Crocodylus), Al, alligators, Ca, caimans, Sn, snakes. $\dagger$ Previously Pseudocrocodilicola; \$ Previously Proterodiplostomum 


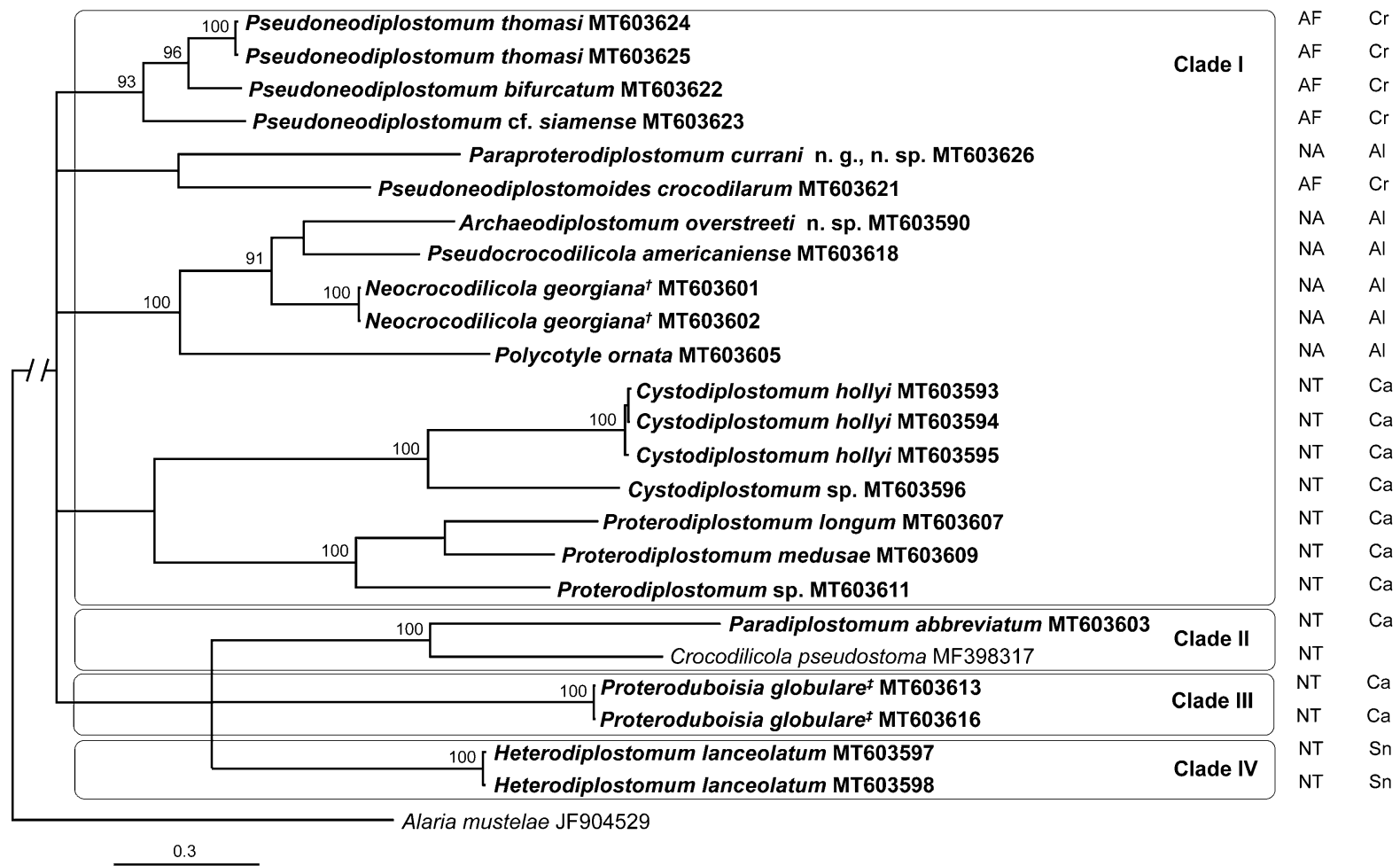

Fig. 3 Phylogenetic relationships between the taxa of the Proterodiplostomidae resulting from Bayesian inference (BI) analysis based on the partial sequences of the mitochondrial $\operatorname{cox} 1$ gene. Bayesian inference posterior probability values are shown above branches; support values lower than $0.80(80 \%)$ are not shown. The scale-bar indicates the number of substitutions per site. Newly generated sequences are highlighted in bold; rectangles indicate the taxa belonging to 4 major monophyletic clades in the $28 \mathrm{~S}$ tree. GenBank accession numbers are provided after the names of species. Biogeographical realms and definitive host groups are indicated in two columns on the right. Abbreviations for biogeographical realms: AF, Afrotropical realm; AU, Australasian realm; NA, Nearctic realm; NT, Neotropical realm. Abbreviations for definitive host groups: Cr, true crocodiles (Crocodylus), Al, alligators, Ca, caimans, Sn, snakes. $\dagger$ Previously Pseudocrocodilicola; $\ddagger$ Previously Proterodiplostomum

American alligators in Mississippi (91\% support) and species of a clade of Pseudoneodiplostomoides and Pseudoneodiplostomum from crocodiles in Africa and Australia. Within the clade of proterodiplostomids from alligators, Paraproterodiplostomum currani n. g., n. sp. formed a sister branch to a $100 \%$ supported clade comprising the remaining taxa (Fig. 2). Among those, Po. ornata + Neocrocodilicola georgiana $\mathrm{n}$. comb. (previously in Pseudocrocodilicola; see discussion below) formed a rather weakly supported clade (85\%), whereas Ps. americaniense and Archaeodiplostomum overstreeti $\mathrm{n}$. sp. formed a clade without meaningful support.

Pseudoneodiplostomoides crocodilarum (Tubangui \& Masiluñgan, 1936) collected from Australian freshwater crocodiles formed a sister branch $(100 \%$ support) to Pseudoneodiplostomum spp. in the clade of proterodiplostomids collected from Co. johnstoni and
Co. niloticus, correspondingly. Pseudoneodiplostomum cf. siamense collected from Australian freshwater crocodiles formed a sister branch (100\% support) to a strongly supported clade (100\%) including the three species of Pseudoneodiplostomum from Nile crocodiles in South Africa.

The second major sub-clade of clade I (100\% support) included members of Cystodiplostomum and Proterodiplostomum from caimans in the Neotropics. Members of each of the two genera formed corresponding $100 \%$ supported clades. Within the Proterodiplostomum clade, the sequence of an unidentified, immature Proterodiplostomum sp. formed a sister branch to the $92 \%$ supported clade of Pr. longum + Pr. medusae.

The $100 \%$ supported clade II included $P a$. abbreviatum that appeared basal to the $100 \%$ supported group of Cr. pseudostoma + Me. gladiolum. Clade III 
included only Proteroduboisia globulare n. comb. (previously in Proterodiplostomum; see discussion below) from a caiman collected in Pantanal, Brazil, while the strongly supported (100\%) small clade IV comprised two species of Heterodiplostomum from a frog and snake in Brazil (Fig. 2).

Upon trimming to the length of the shortest sequence, the cox $1 \mathrm{mtDNA}$ alignment was $520 \mathrm{bp}$ long; no sites were excluded from the analysis. In the phylogenetic tree resulting from the BI analysis (Fig. 3), the topology of the Proterodiplostomidae was much less resolved and differed slightly from the topology in the $28 \mathrm{~S}$ analyses. Clades II, III and IV remained the same as in the $28 \mathrm{~S}$ tree, but clade I split into 6 independent (if low support values are ignored) clades in a polytomy in the cox 1 tree. The majority, but not all, of the well-supported clades in the cox 1 tree represented individual proterodiplostomid genera, namely: (i) two Cystodiplostomum species (100\%); (ii) three Proterodiplostomum spp. (100\%); (iii) Pt. globulare n. comb.; (iv) He. lanceolatum; (v) Pa. abbreviatum + Cr. pseudostoma (100\%); (vi) Po. ornata $+N e$. georgiana $\mathrm{n}$. comb. + Ps. americaniense + Ar. overstreeti n. sp. (100\%); (vii) Pseudoneodiplostomum spp. (93\%); (viii) Pp. currani n. g., n. sp.; and (ix) Pu. crocodilarum (Fig. 3).

It is worth noting that Ps. americaniense and $N e$. georgiana n. comb. (previously in Pseudocrocodilicola; see discussion below) formed a $91 \%$ supported clade with Ar. overstreeti n. sp.; however, the internal topology within this clade was unresolved.

The 3 sequences of $C y$. hollyi along with the 2 sequences each of Pt. globulare n. comb., He. lanceolatum, Ne. georgiana n. comb. and Pe. thomasi formed their own respective $100 \%$ supported clades (Fig. 3).

\section{Genetic variation}

The pairwise nucleotide comparison of proterodiplostomid sequences of 28S (Supplementary Table S1) showed an overall low divergence among genera $(0.5-6.6 \%$ or $5-73$ bases out of 1,106$)$. The pairs Ar. overstreeti n. sp./Ps. americaniense and $C r$. pseudostoma/Pa. abbreviatum had the lowest intergeneric divergence difference in the $28 \mathrm{~S}$ sequences ( $0.5 \%$ or $5-6$ bases). The greatest intergeneric divergence in the $28 \mathrm{~S}$ sequences $(6.6 \%)$ was found in the pairs Pr. medusae (GenBank: MT622342)/He. lanceolatum (MN149353), Me. gladiolum/Pr. longum and Me. gladiolum/Pr. medusae (GenBank: MT622342).

The interspecific genetic divergence among congeneric species in the $28 \mathrm{~S}$ sequences varied greatly across different genera. Our two Cystodiplostomum species showed only $0.4 \%$ (4 bases) difference in their $28 \mathrm{~S}$ sequences and Pseudoneodiplostomum species demonstrated the lowest interspecific divergence in the $28 \mathrm{~S}$ sequences among congeners at $0-1 \%$ or $0-11$ bases (Supplementary Table S1). At the same time, members of Proterodiplostomum as currently accepted, differed by $2.3-4.3 \%$ (25-48 bases) of their $28 \mathrm{~S}$ sequences (Supplementary Table S1).

We did not detect any intraspecific variation in $28 \mathrm{~S}$ sequences in the majority of species with multiple sequenced specimens, namely Ar. overstreeti n. sp. (n =3), Po. ornata $(\mathrm{n}=3)$, Pp. currani n. g., n. sp. $(\mathrm{n}=2)$, Pt. globulare n. comb. $(\mathrm{n}=5)$, Ps. americaniense $(\mathrm{n}=$ 3), Ne. georgiana $\mathrm{n}$. comb. $(\mathrm{n}=4)$, Pe. thomasi $(\mathrm{n}=2)$, and Pe. bifurcatum $(\mathrm{n}=5)$. Only one specimen of $P r$. medusae (GenBank: MT622342) had a single unambiguous base pair difference compared to GenBank: MT622343 and MT622344. It is worth noting our new $28 \mathrm{~S}$ sequence of $\mathrm{He}$. lanceolatum (GenBank: MT622331) and the previously published sequence of He. lanceolatum (GenBank: MN149353) differ by $0.2 \%$ ( 2 bases).

In contrast, cox 1 sequences demonstrated much greater intergeneric variation ranging from $10.4 \%$ (54 bases) between Ps. americaniense and Ne. georgiana n. comb. to $24.8 \%$ (129 bases) between He. lanceolatum and Cystodiplostomum sp. The intrageneric divergence in cox 1 sequences ranged from $6.7 \%$ (35 bases) between Pe. thomasi and Pe. bifurcatum to 16.5\% (86 bases) between Proterodiplostomum sp. and Pr. longum (Supplementary Table S2).

No intraspecific variation was detected among cox 1 sequences of Ar. overstreeti n. sp., Cr. pseudostoma, Po. ornata, Pr. medusae, Pt. globulare n. comb. and $P s$. americaniense. In species that demonstrated intraspecific variation in $\operatorname{cox} 1$, it was dramatically lower than the lowest levels of interspecific divergence and varied between $0.2 \%$ and $0.6 \%$ (1-3 bases) in Cy. hollyi, He. lanceolatum and Ne. georgiana $\mathrm{n}$. comb. (Supplementary Table S2). 


\section{Descriptions of new taxa}

Results of our molecular phylogenetic analysis and morphological examination of freshly collected highquality specimens of proterodiplostomids have revealed the presence of two new species and a new genus in our material from American alligators. Their descriptions are provided below.

\section{Paraproterodiplostomum Tkach, Achatz \& Pulis n. g.}

\section{Diagnosis}

Body bipartite; prosoma elliptical; opisthosoma elongate, cylindrical. Oral and ventral suckers welldeveloped; pseudosuckers absent; holdfast organ large, elliptical, protruding from prosoma. Pharynx moderately developed; caeca extending to near posterior end of opisthosoma. Testes 2, tandem, similar in size, mostly located in last third of opisthosoma. Paraprostate well-developed, claviform; ejaculatory duct joins paraprostate near its distal end to form common male efferent duct that opens into genital atrium. Ovary pretesticular. Vitellarium extends from approximately level of ventral sucker to past posterior testis. Metraterm opens separately from common male efferent duct into genital atrium. Genital atrium opening subterminal on dorsal side. Excretory pore terminal. Nearctic. In Alligator mississippiensis.

Type- and only species: Paraproterodiplostomum currani n. g., n. sp.

ZooBank registration: The Life Science Identifier (LSID) for Paraproterodiplostomum n. g. is urn:lsid:zoobank.org:act:07E1D2C7-D8EB-43A1-89CD-

826B9678E6B2.

Etymology: The name of the new genus reflects its morphological similarity to Proterodiplostomum.

\section{Paraproterodiplostomum currani Tkach, Achatz \& Pulis n. sp.}

Type-host: Alligator mississippiensis (Daudin) (Crocodilia: Alligatoridae).

Type-locality: Pascagoula Wildlife Management Area $\left(30^{\circ} 37^{\prime} 07.2^{\prime \prime} \mathrm{N}, 88^{\circ} 37^{\prime} 08.9^{\prime \prime} \mathrm{W}\right)$, Jackson Co., Mississippi, USA.

Type-material: The type-series consists of 9 fully mature specimens deposited in the HWML. Holotype: HWML 216321, labelled ex Alligator mississippiensis, small intestine, Pascagoula wildlife management area, Jackson Co., Mississippi, USA, 10.vii.2015, coll. V. Tkach. Paratypes: HWML 216322, 216323 (lot of 8 slides), labels identical to the holotype.

Site in host: Small intestine.

ZooBank registration: The Life Science Identifier (LSID) for Paraproterodiplostomum currani n. sp. is urn:1sid:zoobank.org:act:7B9637A3-C820-48EF-

8F22-9CB98C66E4E7.

Etymology: The species is named after Dr Stephen Curran in recognition of his contributions to trematodology, particularly to our knowledge of the trematodes in the Gulf of Mexico and the Gulf Coast, and his invaluable help and camaraderie in numerous collecting trips in the region and beyond.

\section{Description}

[Based on 9 adult specimens; measurements of the holotype are given in text; measurements of the entire series are given in Table 2; see Fig. 4.] Body 6,208 long, consisting of distinct prosoma and opisthosoma; prosoma elliptical, 2,031 long, with maximum width at level of holdfast organ, 965; opisthosoma elongate, cylindrical, 4,177 $\times$ 421. Prosoma:opisthosoma length ratio 0.49. Minuscule scale-like tegumental spines covering anterior part of prosoma almost to level of anterior margin of holdfast organ. Oral sucker subterminal, $111 \times 119$. Pseudosuckers absent. Ventral sucker slightly larger than oral sucker, $131 \times 139$, located near mid-length of prosoma; oral:ventral sucker width ratio $1: 1.17$. Holdfast organ posterior to ventral sucker, protruding from prosoma; subspherical or oval with ventral muscular portion, highly variable in shape, occupying almost entire width and of prosoma, $941 \times 961$. Holdfast organ equal to $46 \%$ of prosoma length. Proteolytic gland extensive, located at base of holdfast organ. Prepharynx not observed. Pharynx oval, $100 \times 80$. Oesophagus slightly longer than pharynx. Caecal bifurcation in anterior third of prosoma; caeca slender, extending to near posterior end of opisthosoma.

Testes 2 , tandem, entire, mostly located in posterior third of opisthosoma; anterior testis $395 \times 324$, posterior testis $459 \times 312$. Seminal vesicle posttesticular, compact, coiled, ventral to posterior testis, continuing as ejaculatory duct before connecting to base of paraprostate to form common male efferent duct. Paraprostate well-developed, claviform, $415 \times$ 128 , with proximal end reaching close to posterior 


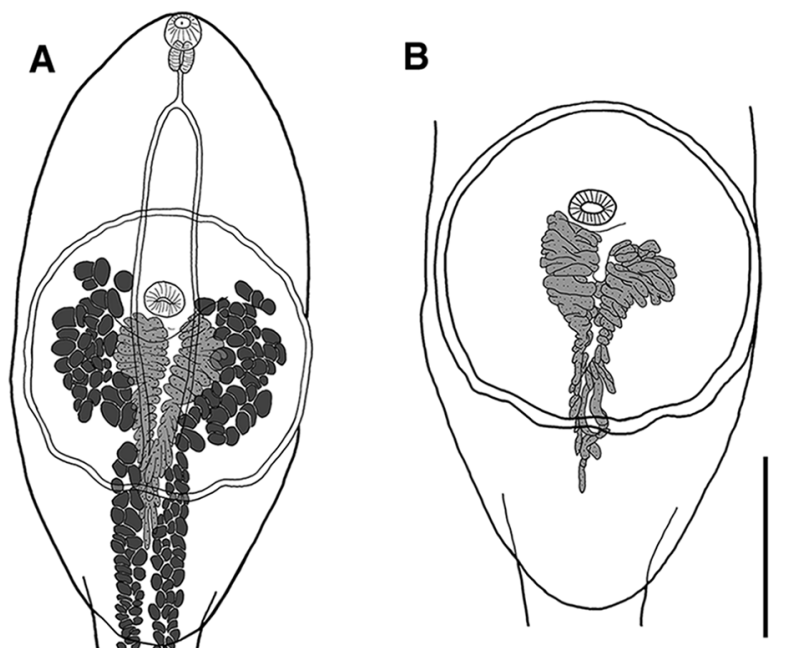

C

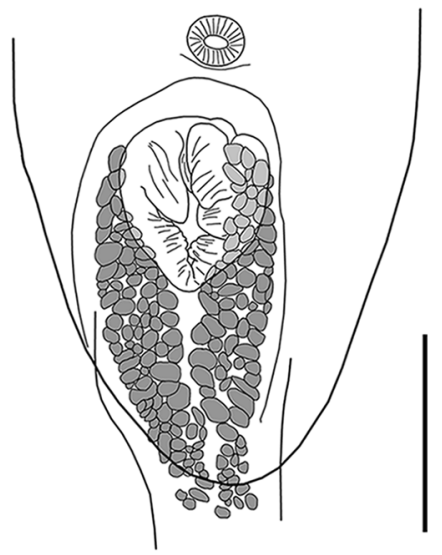

D

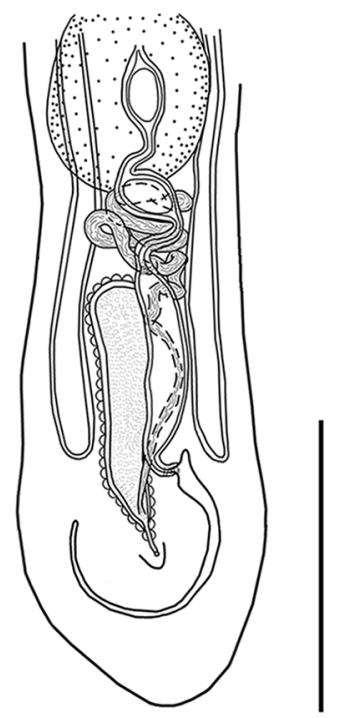

$\mathbf{E}$

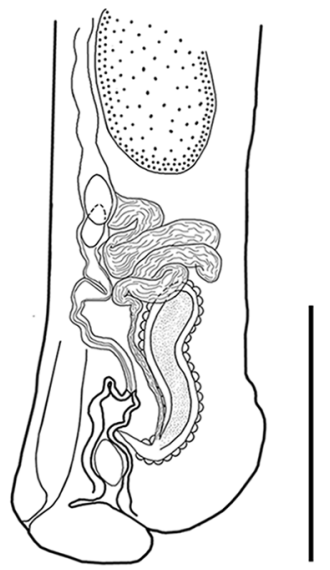

Fig. 4 Paraproterodiplostomum currani n. sp. A, Ventral view of the holotype; B, Proteolytic gland in the holotype; C, Proteolytic gland in a paratype; D, Posterior end of a paratype showing terminal ducts of the reproductive system, ventral view; E, Posterior end of a paratype showing terminal ducts of the reproductive system, lateral view. Scale-bars: A, $1 \mathrm{~mm}$; B-E, $500 \mu \mathrm{m}$ 
Table 2 Metric characters of the two new proterodiplostomid species from Mississippi

\section{Character}

Paraproterodiplostomum currani $\mathbf{n}$.
sp.
$(\mathbf{n}=9)$

Archaeodiplostomum overstreeti $\mathbf{n}$. sp. (n = 4)

\begin{tabular}{|c|c|c|c|c|c|}
\hline Mean \pm SD & Range & CV & Mean \pm SD & Range & $\mathbf{C V}$ \\
\hline $5,779 \pm 430$ & $5,210-6,466$ & 7.4 & $6,753 \pm 776$ & $6,109-7,706$ & 11.5 \\
\hline $2,139 \pm 148$ & $1,947-2,362$ & 6.9 & $3,260 \pm 163$ & $3,063-3,418$ & 5.0 \\
\hline $924 \pm 97$ & $833-1,108$ & 10.5 & $929 \pm 28$ & $905-959$ & 3.0 \\
\hline $3,736 \pm 328$ & $3,368-4,198$ & 8.8 & $3,561 \pm 581$ & $2,915-4,288$ & 16.3 \\
\hline $401 \pm 37$ & $354-451$ & 9.2 & $349 \pm 37$ & $318-390$ & 10.6 \\
\hline $0.58 \pm 0.1$ & $0.49-0.65$ & 10.0 & $0.93 \pm 0.12$ & $0.8-1.1$ & 13.3 \\
\hline $1,015 \pm 135$ & $857-1,308$ & 13.3 & $1,371 \pm 64$ & $1,293-1,430$ & 4.7 \\
\hline $0.18 \pm 0.03$ & $0.15-0.25$ & 18.9 & $0.2 \pm 0.02$ & $0.18-0.22$ & 7.6 \\
\hline $101 \pm 7$ & $90-111$ & 7.0 & $145 \pm 15$ & $128-163$ & 10.5 \\
\hline $111 \pm 6$ & $105-120$ & 5.7 & $149 \pm 7$ & $142-156$ & 4.7 \\
\hline $116 \pm 14$ & 99-132 & 11.6 & $442 \pm 46$ & $409-508$ & 10.5 \\
\hline $136 \pm 17$ & $120-164$ & 12.2 & $444 \pm 39$ & $412-488$ & 8.8 \\
\hline $1: 1.23 \pm 0.16$ & $1: 1.04-1.50$ & 13.1 & $1: 2.85 \pm 0.42$ & $1: 2.44-3.44$ & 14.6 \\
\hline $716 \pm 158$ & $540-941$ & 22.0 & $522 \pm 51$ & $493-598$ & 9.7 \\
\hline $695 \pm 180$ & $533-961$ & 25.9 & $416 \pm 43$ & $387-465$ & 10.3 \\
\hline $0.34 \pm 0.08$ & $0.24-0.46$ & 23.82 & $0.16 \pm 0.01$ & $0.14-0.18$ & 8.8 \\
\hline $0.45 \pm 0.11$ & $0.31-0.56$ & 25.0 & $0.7 \pm 0.04$ & $0.65-0.74$ & 10.3 \\
\hline $0.04 \pm 0.05$ & $0-0.12$ & 128.3 & $0.28 \pm 0.04$ & $0.23-0.31$ & 13.8 \\
\hline $105 \pm 7$ & $98-118$ & 6.7 & $94 \pm 14$ & 79-106 & 14.6 \\
\hline $83 \pm 4$ & $78-89$ & 4.8 & $88 \pm 4$ & $85-93$ & 4.7 \\
\hline $114 \pm 31$ & $67-162$ & 27.2 & $132 \pm 28$ & $107-163$ & 21.4 \\
\hline $304 \pm 50$ & $221-395$ & 16.5 & $215 \pm 28$ & $176-243$ & 13.1 \\
\hline $252 \pm 35$ & $218-324$ & 13.8 & $220 \pm 19$ & 199-236 & 8.6 \\
\hline $350 \pm 51$ & $287-459$ & 14.7 & $227 \pm 30$ & $193-248$ & 13.0 \\
\hline $259 \pm 32$ & $221-312$ & 12.5 & $224 \pm 26$ & $199-250$ & 11.4 \\
\hline $0.23 \pm 0.03$ & $0.20-0.27$ & 11.3 & $0.52 \pm 0.05$ & $0.46-0.57$ & 9.0 \\
\hline $880 \pm 83$ & 776-978 & 9.4 & $1,279 \pm 472$ & $822-1,874$ & 36.9 \\
\hline $398 \pm 41$ & $344-479$ & 10.2 & $235 \pm 19$ & $218-255$ & 7.9 \\
\hline $125 \pm 15$ & $102-143$ & 11.7 & $108 \pm 6$ & $101-112$ & 5.9 \\
\hline $272 \pm 32$ & $215-324$ & 11.8 & $114 \pm 15$ & $99-129$ & 13.6 \\
\hline $194 \pm 19$ & $162-228$ & 10.0 & $112 \pm 14$ & $96-129$ & 12.1 \\
\hline $262 \pm 48$ & $228-296$ & 18.4 & $321 \pm 34$ & $285-352$ & 10.5 \\
\hline $20.6 \pm 13.1$ & $1-36$ & 63.7 & $60 \pm 23$ & $29-84$ & 38.3 \\
\hline $92 \pm 3$ & $85-96$ & 3.1 & $89 \pm 6$ & $78-97$ & 6.5 \\
\hline $55 \pm 4$ & $46-59$ & 7.1 & $51 \pm 3$ & $47-55$ & 6.4 \\
\hline $0.54 \pm 0.13$ & $0.41-0.77$ & 24.8 & $0.52 \pm 0.04$ & $0.48-0.56$ & 7 \\
\hline $0.22 \pm 0.05$ & $0.15-0.29$ & 22.9 & $0.17 \pm 0.02$ & $0.15-0.19$ & 10.8 \\
\hline
\end{tabular}

Abbreviations: $\mathrm{CV}$, coefficient of variation; $\mathrm{SD}$, standard deviation 
testis, surrounded by gland cells. Common male efferent duct opening into genital atrium separately from female opening.

Ovary pretesticular, oval or subspherical $287 \times$ 228. Oötype, Mehlis' gland and uterine seminal receptacle inter-testicular. Vitelline follicles located around holdfast organ in prosoma and extending posteriorly to about level of paraprostate, ventral and lateral to gonads. Vitelline reservoir intertesticular. Uterus ventral to gonads, extending anteriorly from ovary to near junction of prosoma and opisthosoma before turning and extending posteriorly. Metraterm opening into genital atrium separately from common male efferent duct; genital atrium opening subterminal on dorsal side. Uterus contains numerous eggs (85-96 $\times$ 46-59). Genital atrium subterminal, on dorsal side.

Excretory vesicle not well-observed. Excretory pore terminal.

\section{Remarks}

The new genus can be differentiated from all other known proterodiplostomid genera based on a range of morphological characters. Paraproterodiplostomum currani n. g., n. sp. differs from Heterodiplostomum by the lack of a muscular pouch surrounding the paraprostate (Figs. 4, 5G, S); additionally, Pp. currani n. g., n. sp. differs from He. lanceolatum by $4.2 \%$ (36 bases) in the $28 \mathrm{~S}$ sequence nucleotide positions and up to $20.8 \%$ (107 bases) in cox 1 sequences (Supplementary Tables S1, S2). The new genus can be readily differentiated from Capsulodiplostomum Dwivedi, 1966 due to the lack of the muscular pouch enclosing the paraprostate, ejaculatory duct and metraterm. Unlike the members of Mesodiplostomum and Proalarioides Yamaguti, 1933 which lack a visible paraprostate, the new genus has a well-developed paraprostate (Figs. 4, 5G, T, U). The new genus and Me. gladiolum differ by $3.8 \%$ (42 bases) in the $28 \mathrm{~S}$ sequences (Supplementary Table S1). Paraproterodiplostomum currani n. g., n. sp. is readily distinguishable from Ophiodiplostomum Dubois, 1936 species based on the relative size of the holdfast organ. In Pp. currani n. g., n. sp. the holdfast organ occupies on average 34\% (24-46\%) of the prosoma, while the holdfast organ of Ophiodiplostomum species is relatively larger and occupies approximately half of the prosoma length.
The terminal ducts of the male and female reproductive systems in Pp. currani n. g., n. sp. open separately into the genital atrium. In contrast, the metraterm of Archaeodiplostomum, Crocodilicola, Polycotyle, and Pseudocrocodilicola species joins the common male efferent duct prior to reaching the genital atrium (Fig. 5A-C, E-G). Whereas the ejaculatory duct in the new genus joins the paraprostate, in Cheloniodiplostomum Sudarikov, 1960, Cystodiplostomum, Herpetodiplostomum Dubois, 1936, Massoprostatum Caballero, 1948, Paradiplostomum, and Prolecithodiplostomum Dubois, 1936 the paraprostate opens separately from the ejaculatory duct and metraterm (Figs. 4, 5G, M-O, Q, R). The new genus differs from Archaeodiplostomum, Crocodilicola, Polycotyle, Pseudocrocodilicola, Cystodiplostomum and Paradiplostomum spp. by 1.5-3.9\% (16-43 bases) in the $28 \mathrm{~S}$ sequences and 17.3-22.3\% (90-116 bases) in the cox 1 sequences (Supplementary Tables S1, S2).

Paraproterodiplostomum currani n. g., n. sp. clearly differs from Proterodiplostomum species by the absence of the sucker-like structure in the genital atrium. Furthermore, the ejaculatory duct of Paraproterodiplostomum $\mathrm{n}$. g. joins the paraprostate at its base, whereas the ejaculatory duct of Proterodiplostomum does not join the paraprostate. However, the ejaculatory duct of Proterodiplostomum may later join the efferent duct of the paraprostate (Figs. 4, 5G, J, K). In addition, the sequences of the new genus demonstrate significant differences from Proterodiplostomum species in both the $28 \mathrm{~S}(4.8-5.4 \%$ or $53-60$ bases) and $\operatorname{cox} 1$ (19-21.3\% or 99-116 bases) genes (Supplementary Tables S1, S2).

The new genus has a well-developed paraprostate compared to the relatively small and weaker developed paraprostate in Pseudoneodiplostomum. The two genera can be further differentiated based on the position of the ejaculatory duct and paraprostate juncture. In Pp. currani n. g., n. sp. the ejaculatory duct joins the paraprostate at its base, whereas in members of Pseudoneodiplostomum the ejaculatory duct joins the paraprostate between its midlength and proximal (anterior) end (Figs. 4, 5G, H). In addition, the new genus differs from members of Pseudoneodiplostomum by $2.6-2.7 \%$ (29-30 bases) in the $28 \mathrm{~S}$ sequences and by $16.3-18.1 \%$ (85-94 bases) in the $\operatorname{cox} 1$ sequences (Supplementary Tables S1, S2). 

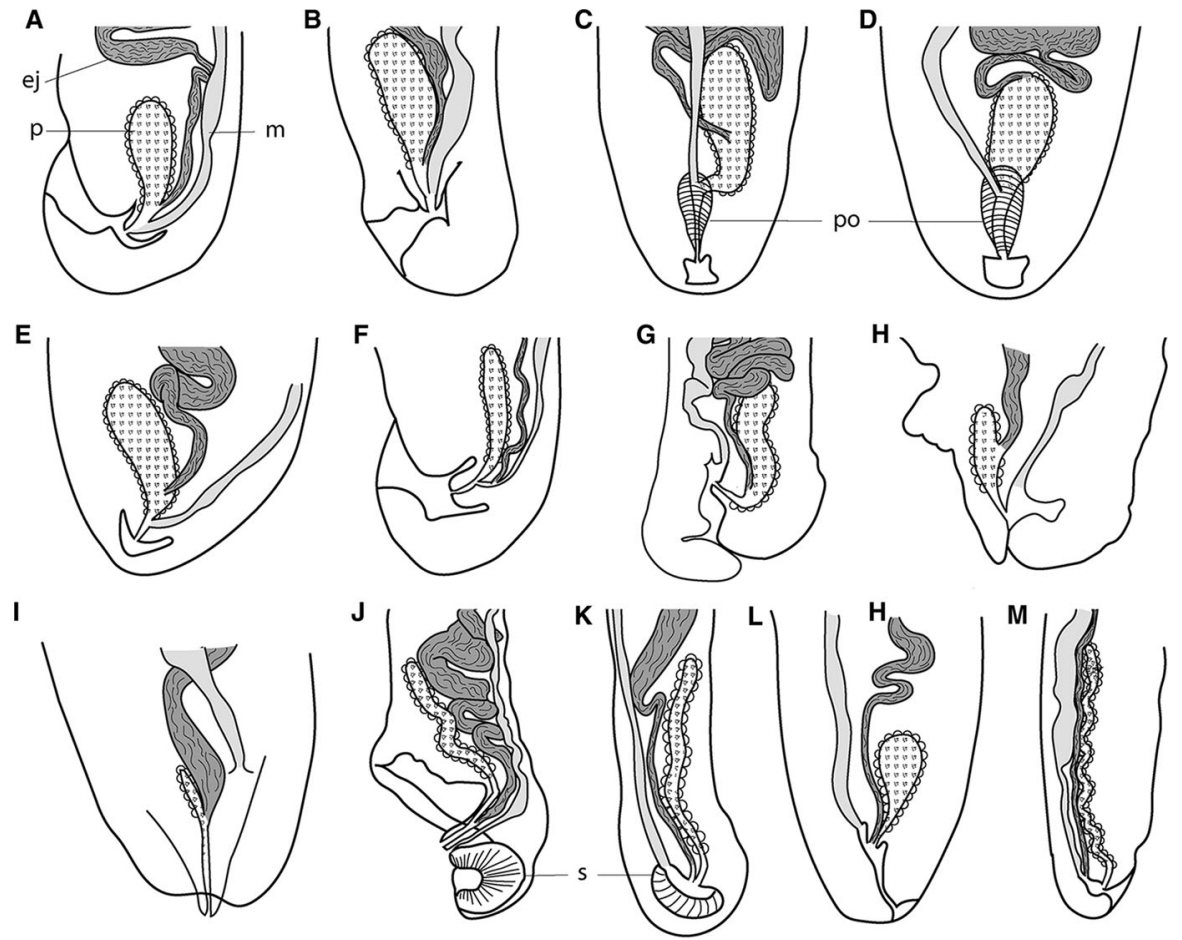

$\mathbf{N}$
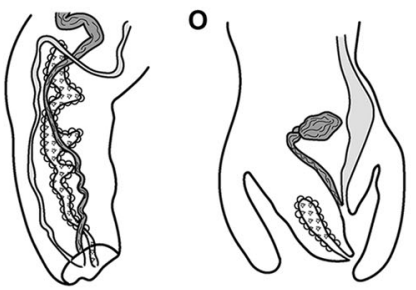

$\mathbf{P}$

a
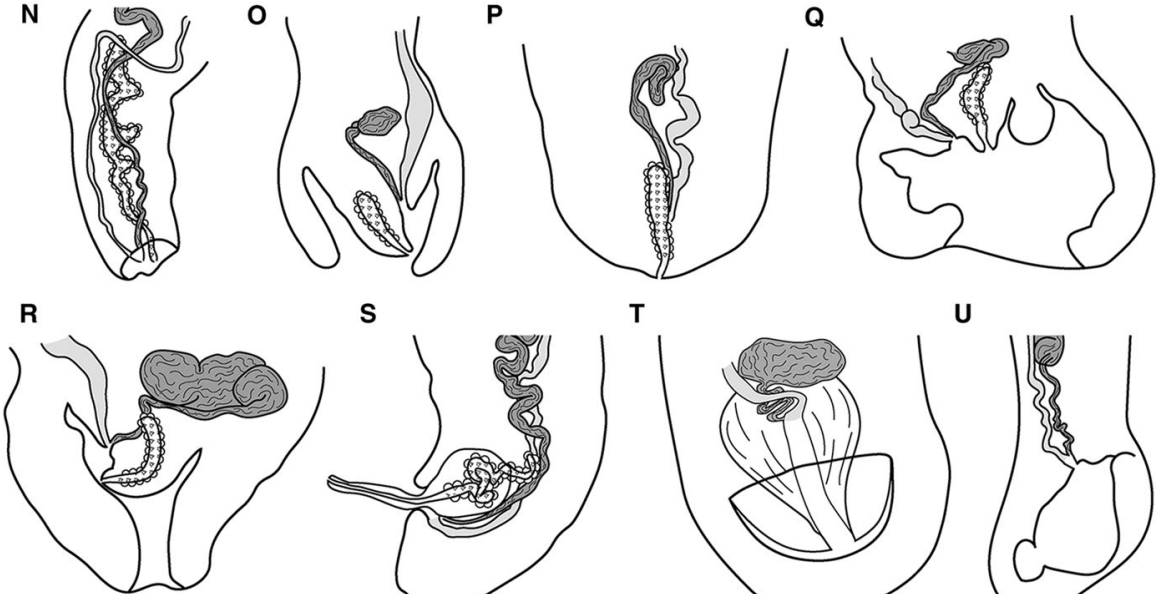

S

T
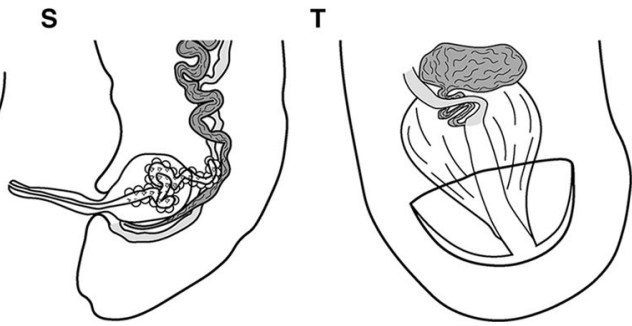

U

Fig. 5 Topologies of terminal reproductive ducts of representative species of all currently accepted proterodiplostomid genera with the exception of Capsulodiplostomum and Cystodiplostomum. Capsulodiplostomum was omitted due to a lack of any previously published, quality illustrations of the terminal ducts. Cystodiplostomum was not drawn separately as the topology of its terminal reproductive ducts is identical to Prolecithodiplostomum constrictum. A, Archaeodiplostomum acetabulatum, lateral view; B, Archaeodiplostomum overstreeti n. sp., lateral view; C, Pseudocrocodilicola americaniense, ventral view; D, Neocrocodilicola georgiana n. comb., ventral view; E, Crocodilicola pseudostoma, ventral view; F, Polycotyle ornata, lateral view; G, Paraproterodiplostomum currani n. g., .n. sp., lateral view; H, Pseudoneodiplostomum gabonicum, lateral view; I, Pseudoneodiplostomoides crocodilarum, dorsal view; J, Proterodiplostomum longum, lateral view; K, Proterodiplostomum medusae, lateral view; L, Proteroduboisia globulare $\mathrm{n}$. comb., lateral view; M, Prolecithodiplostomum constrictum, lateral view; N, Massoprostatum longum, ventral view; O, Paradiplostomum abbreviatum, lateral view; P, Ophiodiplostomum spectabile, dorsal view; Q, Cheloniodiplostomum testudinis, lateral view; R, Herpetodiplostomum caimancola, lateral view; S, Heterodiplostomum lanceolatum, lateral view; T, Proalarioides serpentis, ventral view; U, Mesodiplostomum gladiolum, lateral view. A, C-F, after Byrd \& Reiber (1942); H, after Dubois (1948); I, after Yamaguti (1954); J, M, P-S, U, after Dubois (1936); K, L, O, after Catto \& Amato (1994); N, T, after Sudarikov (1960). Abbreviations: b, muscular bulb; ej, ejaculatory duct; $\mathrm{m}$, metraterm; $\mathrm{p}$, paraprostate; $\mathrm{s}$, muscular sucker-like structure 
Archaeodiplostomum overstreeti Tkach, Achatz \& Pulis n. sp.

Type-host: Alligator mississippiensis (Daudin) (Crocodilia: Alligatoridae).

Type-locality: Pascagoula Wildlife Management Area $\left(30^{\circ} 37^{\prime} 07.2^{\prime \prime} \mathrm{N}, 88^{\circ} 37^{\prime} 08.9^{\prime \prime} \mathrm{W}\right)$, Jackson Co., Mississippi, USA.

Type-material: The type-series consists of 4 fully mature specimens deposited in the HWML. Holotype: HWML 216298, labelled ex A. mississippiensis, small intestine, Pascagoula wildlife management area, Jackson Co., Mississippi, USA, 17.viii.2010, coll. V. Tkach. Paratypes: HWML 216299 (lot of 3 slides), labels identical to the holotype.

Site in host: Small intestine.

ZooBank registration: The Life Science Identifier (LSID) for Archaeodiplostomum overstreeti n. sp. is urn:1sid:zoobank.org:act:990F2528-BE34-46A78810-1062D7787C70.

Etymology: The species is named after Dr Robin Overstreet in recognition of his numerous contributions to helminthology including helminths of crocodilians, and his invaluable help with collection of specimens in Mississippi.

\section{Description}

[Based on 4 adult specimens; measurements of the holotype are given in text; measurements of the entire series are given in Table 2; see Fig. 6.] Body 6,109 long, consisting of prosoma and opisthosoma; prosoma elongate, 3,194 long, much wider than opisthosoma, with maximum width at level of holdfast organ, 959; opisthosoma elongate, cylindrical, 2,915 × 340, similar in length to prosoma; prosoma:opisthosoma length ratio 1.1. Minuscule scale-like tegumental spines covering anterior part of prosoma and reaching level of posterior margin of ventral sucker. Oral sucker subterminal, $138 \times 142$. Pseudosuckers absent. Prepharynx not observed. Pharynx oval, $79 \times 93$. Oesophagus approximately twice as long as pharynx. Caecal bifurcation in anterior third of prosoma; caeca slender, blind, extending to near posterior end of opisthosoma. Ventral sucker $508 \times 488$, much larger than oral sucker, typically located somewhat anterior to mid-length of prosoma. Oral sucker:ventral sucker width ratio 1:3.4. Holdfast organ $496 \times 387$, posterior to ventral sucker, located in last third of prosoma, oval with ventral muscular portion. Holdfast organ equal to $16 \%$ of prosoma length. Proteolytic gland at base of holdfast organ.

Testes 2 , tandem, smooth, mostly located in middle third of opisthosoma; anterior testis $176 \times 225$, posterior testis $193 \times 222$. Seminal vesicle posttesticular, elongated, sinuous, continuing as sinuous ejaculatory duct prior to joining base of paraprostate to form common male efferent duct. Paraprostate welldeveloped, claviform, $220 \times 101$, surrounded by gland cells. Common male efferent duct and metraterm join to form a common duct almost immediately prior to opening into genital atrium.

Ovary immediately pretesticular, subspherical, 99 $\times$ 96. Oötype and Mehlis' gland intertesticular. Seminal receptacle subspherical, immediately dorsal to oötype, smaller than ovary. Vitelline follicles distributed from level immediately posterior to ventral sucker to immediately anterior to paraprostate, ventral and lateral to gonads. Vitelline reservoir intertesticular. Uterus ventral to gonads, extending anteriorly from ovary to about level of prosoma and opisthosoma before turning and extending posteriorly and eventually transitioning into metraterm. Uterus contains numerous eggs $(78-97 \times 47-55)$. Genital atrium subterminal, on dorsal side.

Excretory vesicle not observed. Excretory pore terminal.

\section{Remarks}

The new species clearly belongs to Archaeodiplostomum based on the large ventral sucker, a welldeveloped claviform paraprostate, and an ejaculatory duct that joins the base of the paraprostate to form a common male efferent duct that subsequently merges with the metraterm to form a common duct. At present, Archaeodiplostomum includes a single species $A r$. acetabulata.

Archaeodiplostomum overstreeti $\mathrm{n}$. sp. differs from Ar. acetabulata by having a more elongated prosoma compared to the pyriform-shaped prosoma in $A r$. acetabulata (Fig. 6; Byrd \& Reiber, 1942). The new species can also be differentiated from Ar. acetabulata by having a longer body $(6,109-7,706 \mu \mathrm{m}$ in the new species $v s$ 4,800-5,960 $\mu \mathrm{m}$ in Ar. acetabulata) and a typically smaller holdfast organ $(493-598 \times 387-465$ $\mu \mathrm{m}$ in the new species $v s 570-840 \times 500-740 \mu \mathrm{m}$ in Ar. acetabulata). In addition, Ar. overstreeti n. sp. has 


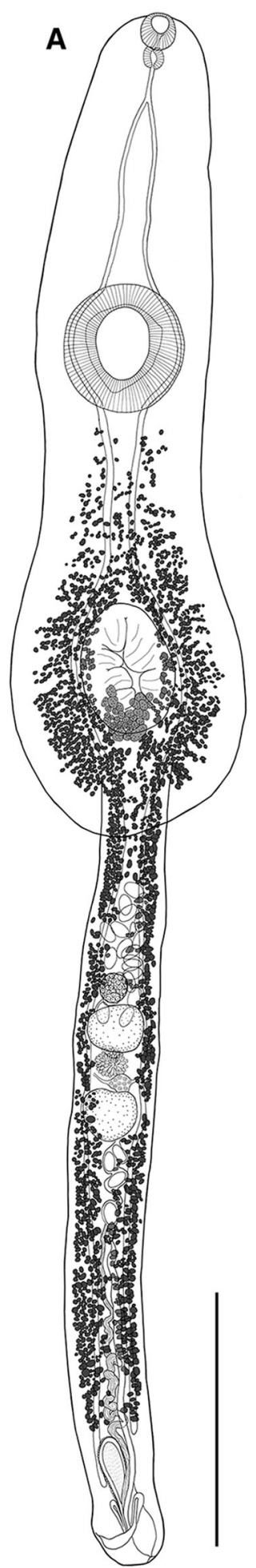

\section{B}

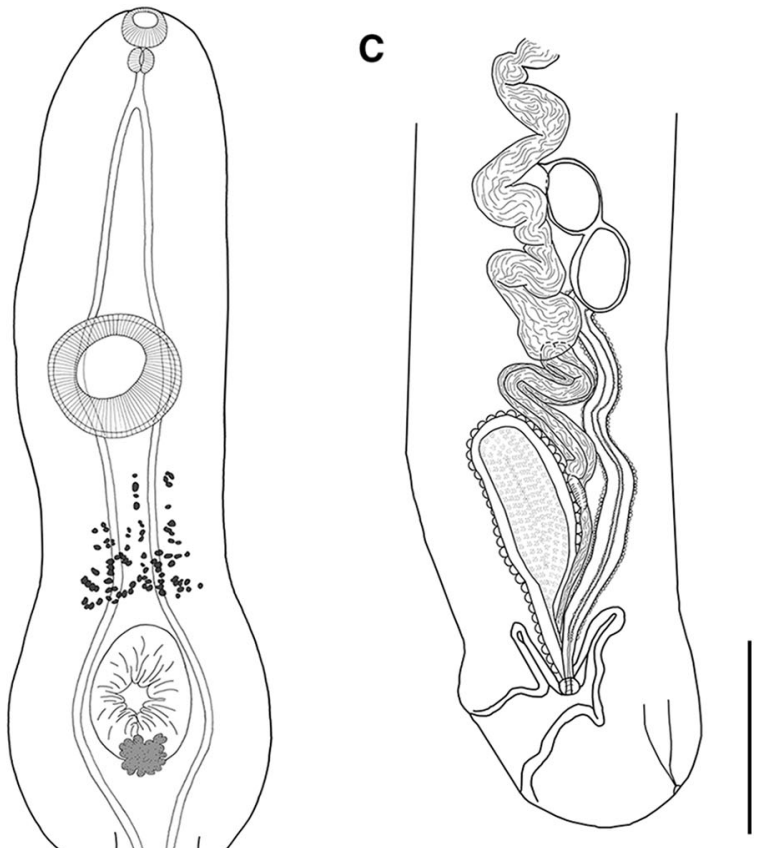

Fig. 6 Archaeodiplostomum overstreeti n. sp. A, Ventral view of the holotype; B, Ventral view of a paratype, anteriormost and posteriormost vitelline follicles are shown for clarity; C, Posterior end of a paratype showing terminal ducts of the reproductive system, lateral view. Scale-bars: A, B, $1 \mathrm{~mm} ; \mathrm{C}, 200 \mu \mathrm{m}$ 
substantially smaller paraprostate $(218-255 \times$ $101-112 \mu \mathrm{m}$ in the new species vs $310-450 \times$ $120-160 \mu \mathrm{m}$ in Ar. acetabulata), ovary and testes.

Metacercariae of Ar. overstreeti n. sp. were recovered and sequenced from $N$. fasciata and $N$. cyclopion in Mississippi. These snakes are common in the areas where the alligators were captured. The specimen sequenced from the $N$. fasciata was found excysted in the stomach, but was not sexually mature. Gut contents of the snake contained unidentifiable fish remnants. The specimen sequenced from the $N$. cyclopion was found in the mesenteries, thus providing the first evidence that snakes can likely act as paratenic hosts for these digeneans, which are parasitic as adults in alligators.

\section{Discussion}

\section{Abandonment of the subfamily-based system of the Proterodiplostomidae}

Our molecular phylogenetic analysis of a broad diversity of proterodiplostomids from a variety of hosts from four continents strongly supports the monophyly of the Proterodiplostomidae. At the same time, our results do not support the most recent (or any of the previous) systematic arrangement of some of the taxa, particularly the current subfamily structure within the family as presented by Niewiadomska (2002). Although, this is true for both $28 \mathrm{~S}$ and cox 1 based phylogenies, we primarily rely on the $28 \mathrm{~S}$ data in our subsequent considerations due to the much higher resolution at the suprageneric level provided by this gene. As has been previously suggested, the analyses based on cox 1 data produce low resolution and numerous polytomies most likely resulting from the mutation saturation effect. Considering that the Proterodiplostomidae clearly is an ancient group of digeneans, combined with the fact that crocodilians live in warm climates where parasite life-cycles continue throughout the year, these parasites evolved over a great span of evolutionary time in terms of the number of generations. This most likely resulted in a greater mutation accumulation in fast mutating mitochondrial genes leading to lower resolution in the cox 1 trees compared to those produced by the analyses of the slower mutating $28 \mathrm{~S}$ gene. As noted by previous authors (e.g. Locke et al., 2018; Queiroz et al., 2020), the usefulness of commonly sequenced nuclear ribosomal and mitochondrial genes for phylogenetic inference at different taxonomic levels varies and necessitates careful assessment.

While the early systematics of the Proterodiplostomidae were based on a variety of characters traditionally used in digenean taxonomy, Brooks et al. (1992) proposed a revised system of the family with an emphasis on the structure of the terminal parts of the reproductive system. These authors split the Proterodiplostomidae based on the following four conditions: (i) paraprostate fused with ejaculatory duct and metraterm (referred to as uterus by Brooks et al. [1992]) opening separately; (ii) paraprostate and ejaculatory duct fused, then metraterm fused with common male efferent duct; (iii) paraprostate fused first with metraterm and then with ejaculatory duct; and (iv) paraprostate opening separately. This led Brooks et al. (1992) to propose two subfamilies, the Heterodiplostominae Dubois, 1936 incertae sedis, sedis mutabilis (Heterodiplostomum and Ophiodiplostomum) and the Proterodiplostominae with the latter divided into three tribes: (i) Pseudoneodiplostomini Dubois, 1936 sedis mutabilis (Neelydiplostomum Gupta, 1958, currently considered a synonym of Herpetodiplostomum and Pseudoneodiplostomum); (ii) Pseudocrocodilicolini Byrd \& Reiber, 1942 sedis mutabilis (Archaeodiplostomum, Crocodilicola, Pseudocrocodilicola and Polycotyle); and (iii) Proterodiplostomini Dubois, 1936 sedis mutabilis (Cystodiplostomum, Herpetodiplostomum, Massoprostatum, Mesodiplostomum, Paradiplostomum, Prolecithodiplostomum and Proterodiplostomum).

Our analyses supported neither the subfamilies nor the tribes Pseudocrocodilicolini (with a caveat that the Crocodilicola sequence in GenBank originated from a metacercaria) and Proterodiplostomini of Brooks et al. (1992).

In the most recent revision of the Proterodiplostomidae, Niewiadomska (2002) did not accept the system proposed by Brooks et al. (1992). Her system included five subfamilies: Massoprostatinae, Ophiodiplostominae, Polycotylinae, Proalarioidinae, and Proterodiplostominae. Our molecular phylogenetic analyses included five genera of the Polycotylinae (Crocodilicola, Cystodiplostomum, Paradiplostomum, Pseudocrocodilicola and Polycotyle), four genera of the Proterodiplostominae (Archaeodiplostomum, Mesodiplostomum, 
Pseudoneodiplostomum and Proterodiplostomum) and one genus of the Ophiodiplostominae (Heterodiplostomum). Our analyses revealed the Polycotylinae and Proterodiplostominae to be clearly paraphyletic (Figs. 1-3).

Our molecular phylogenetic results did not support any of the previously proposed systems of the Proterodiplostomidae including the most recent system proposed by Niewiadomska (2002). The use of the organisation of the terminal parts of the reproductive system as the main basis for the systematic arrangement of the proterodiplostomids was also not supported, although these characters are certainly useful for differentiation among genera and species. Our analyses do not show a clear association between well-supported proterodiplostomid clades and the structure of their terminal reproductive ducts (Figs. 2, 3, 5). For instance, in both 28S analyses (Figs. 1,2) the representative of Paraproterodiplostomum n. g., which has a uterus that opens into the genital atrium separately from a common male efferent duct, formed a clade with $\mathrm{Ar}$ chaeodiplostomum, Neocrocodilicola n. comb., Polycotyle and Pseudocrocodilicola, which all have the ejaculatory duct, paraprostate and metraterm form a common duct. Likewise, members of Cystodiplostomum, which have a paraprostate that opens separate from the ejaculatory duct and metraterm, formed a clade with the Proterodiplostomum spp. (excluding Pt. globulare formerly included in Proterodiplostomum; see discussion below) possessing a metraterm that opens separately from the ejaculatory duct and the paraprostate. Although, the level of paraprostate development and the arrangement of terminal ducts of the reproductive system do not seem to be useful for identifying subfamilies of proterodiplostomids, these features are definitely suitable for differentiation among genera. We therefore provide schematic diagrams of almost all proterodiplostomid genera based on the original illustrations (Fig. 5).

Based on all previously available and new molecular as well as morphological data, we abandon the subfamily structure of the Proterodiplostomidae. This decision is reminiscent of other large digenean families that traditionally had a complex taxonomic structure, e.g. the Cryptogonimidae Ward, 1917, the Echinostomatidae Looss, 1899, and the Dicrocoeliidae Looss, 1899. In all those cases, the increasing amount of phylogenetic data indicated lack of support for existing subfamilies, which resulted in the abandonment of the subfamilies in all three families (Miller \& Cribb, 2008; Tkach et al., 2016, 2018). This allows us to look at the evolution and taxonomy of this group unobstructed by the systematic schemes based on ambiguous characters with unclear evolutionary history and relative weight. We believe this will accelerate the development of a natural classification system of the Proterodiplostomidae, based on a combination of molecular phylogenetic data and better understood morphological criteria.

\section{Revision and additional systematic changes at genus level}

\section{The status of Pseudocrocodilicola}

Until now the genus Pseudocrocodilicola contained two species: Ps. americaniense (type-species) and Ps. georgiana (see Byrd \& Reiber, 1942; Dubois, 1979). These species did not form a monophyletic clade in any of our analyses. Pseudocrocodilicola georgiana clustered with Po. ornata ( $85 \%$ support) in the $28 \mathrm{~S}$ analysis of the Proterodiplostomidae and appeared as a separate branch in the cox 1 tree (Figs. 2, 3), whereas Ps. americaniense consistently formed a poorly supported clade with Ar. overstreeti n. sp. in both $28 \mathrm{~S}$ and $\operatorname{cox} 1$ analyses (Figs. 2, 3).

Besides the low branch support in the phylogenetic analyses, species of Archaeodiplostomum and Pseudocrocodilicola have very significant morphological differences, definitely warranting their placement into separate genera. Archaeodiplostomum spp. are characterised by having a very large ventral sucker, a prosoma and opisthosoma of similar length, vitellarium distributed in both the prosoma, and the opisthosoma and an ejaculatory duct that joins the paraprostate at its base. In contrast, members of Pseudocrocodilicola have a prosoma that is typically much longer than the opisthosoma, vitellarium primarily limited to the prosoma, and a muscular pouch surrounding the common duct. In addition, Ps. americaniense has an ejaculatory duct that joins the paraprostate at its middle and Ps. georgiana has an ejaculatory duct that joins the paraprostate at its proximal (anterior) end (Byrd \& Reiber, 1942; Fig. 5).

The two species of Pseudocrocodilicola also have significant morphological differences beyond the 
position of the junction of the ejaculatory duct with the paraprostate. The vitellarium of Ps. americaniense does not extend anteriorly to the level of the ventral sucker, whereas the vitellarium of Ps. georgiana always extends anteriorly beyond the level of the ventral sucker. Additionally, the metraterm of $P$ s. americaniense joins the common male efferent duct some distance after it exits the paraprostate to form the common duct (similar to that in Archaeodiplostomum spp.), whereas the metraterm of Ps. georgiana joins the distal (posterior) end of the paraprostate to form the common duct (Fig. 5C, D) (Byrd \& Reiber, 1942).

Based on the phylogenetic position, genetic distances and the above morphological differences between the two Pseudocrocodilicola species, we believe Ps. georgiana needs to be transferred to a new genus. Therefore, we establish Neocrocodilicola $\mathrm{n}$. g. with Neocrocodilicola georgiana $\mathrm{n}$. comb. as the typeand only species. An amended diagnosis of Pseudocrocodilicola and diagnosis of Neocrocodilicola $\mathrm{n}$. g. are provided below.

\section{Pseudocrocodilicola Byrd \& Reiber, 1942}

\section{Diagnosis}

[After Niewiadomska (2002), amended.] Body distinctly bipartite; prosoma flattened, lanceolate, longer than cylindrical opisthosoma. Oral sucker smaller than ventral sucker. Pseudosuckers absent. Ventral sucker situated in middle or anterior to middle of prosoma; holdfast organ rather small, oval, with median slit bordered by papillae. Pharynx similar in size to oral sucker; caeca reaching level of paraprostate. Gonads occupying most of opisthosoma. Testes 2, tandem; paraprostate small, muscular, ellipsoidal, surrounded by relatively few, large gland-cells. Ejaculatory duct joins paraprostate near its midpoint. Ovary pretesticular; oötype intertesticular. Vitellarium distributed throughout posterior two thirds of prosoma, anterior extent at level of or before ventral sucker. Metraterm joins common male efferent duct to form common duct surrounded by thick-walled muscular pouch and opening into genital atrium. Excretory pore terminal. In Alligator mississippiensis. Nearctic.

Type-species: Pseudocrocodilicola americaniense Byrd \& Reiber, 1942.

\section{Neocrocodilicola Tkach, Achatz \& Pulis n. g.}

\section{Diagnosis}

Body distinctly bipartite; prosoma flattened, lanceolate, longer than cylindrical opisthosoma. Oral sucker smaller than ventral sucker. Pseudosuckers absent. Ventral sucker situated in middle or anterior to middle of prosoma; holdfast organ rather small, oval, with median slit bordered by papillae. Pharynx similar in size to oral sucker; caeca reaching level of paraprostate. Gonads occupying most of opisthosoma. Testes 2, tandem; paraprostate small, muscular, ellipsoidal, surrounded by relatively few large gland cells. Ejaculatory duct joins proximal end of paraprostate. Ovary pretesticular; oötype intertesticular. Vitellarium distributed throughout posterior two thirds of prosoma, always extending anteriorly beyond ventral sucker, sometimes slightly extending into opisthosoma. Metraterm joins common male efferent duct to form common duct surrounded by thick-walled muscular pouch and opening into genital atrium. Excretory pore terminal. In Alligator mississippiensis. Nearctic. Type-species: Neocrocodilicola georgiana (Byrd \& Reiber, 1942) Tkach, Achatz \& Pulis n. comb.

ZooBank registration: The Life Science Identifier (LSID) for Neocrocodilicola n. g. is urn:lsid:zoobank.org:act:AE93B5BB-20F6-4FE5-8FFAE09BF724541F

Etymology: The generic name reflects the parasitism in crocodilians and the fact that the name Crocodilicola is already preoccupied.

\section{Remarks}

Neocrocodilicola n. g. differs by $1.9-5.3 \%$ of nucleotide positions in $28 \mathrm{~S}$ sequences and $10.4-21.7 \%$ of nucleotide positions in cox 1 sequences from all other genera with available DNA sequence data (Supplementary Tables S1, S2).

Neocrocodilicola n. g. can be differentiated from Heterodiplostomum by the lack of a muscular pouch surrounding the paraprostate (Fig. 5D, S). Neocrocodilicola n. g. also lacks a muscular pouch enclosing the paraprostate, ejaculatory duct and metraterm found in Capsulodiplostomum. Unlike Mesodiplostomum and Proalarioides, Neocrocodilicola n. g. has a defined paraprostate (Fig. 5D, T, U). Neocrocodilicola $\mathrm{n}$. g. has a relatively much smaller 
holdfast organ compared to Ophiodiplostomum, in which it occupies approximately half of the prosoma.

The metraterm of Neocrocodilicola $\mathrm{n}$. g. joins the common male efferent duct to form the common duct. In contrast, Proterodiplostomum, Pseudoneodiplostomum and Paraproterodiplostomum n. g. possess a metraterm which opens separately from the male ducts (Fig. 5D, G, H, J, K). The ejaculatory duct of Neocrocodilicola n. g. joins the proximal half of the paraprostate (Fig. 5D), while in Cystodiplostomum, Herpetodiplostomum, Massoprostatum, Paradiplostomum and Prolecithodiplostomum the paraprostate, the ejaculatory duct and the metraterm open separately into the genital atrium (Fig. 5M, N, O, R).

Neocrocodilicola n. g. can be easily differentiated from Polycotyle, Crocodilicola and Archaeodiplostomum by the presence of a muscular pouch surrounding the common duct. Furthermore, Neocrocodilicola n. g. does not possess small suckers along the opisthosoma, which are characteristic of Polycotyle. The vitellarium in Neocrocodilicola $\mathrm{n}$. g. is not limited to the area around the holdfast organ as in Crocodilicola.

The ejaculatory duct in Neocrocodilicola n. g. joins the near the proximal end of the paraprostate, whereas in Archaeodiplostomum and Pseudocrocodilicola it joins either the common efferent male duct or the distal end of the paraprostate, respectively (Fig. 5B-D).

\section{The status of Proterodiplostomum}

Proterodiplostomum at present includes six species and is the most speciose genus of proterodiplostomids in the Neotropics. All known species have an ejaculatory duct and paraprostate that open side by side or with a common pore (without a common male efferent duct) and a metraterm which opens separately from the male ducts (Dubois, 1979; Catto \& Amato, 1994). Two Proterodiplostomum species from caimans (the type-species $P r$. longum and $P r$. tumidulum) were described with a sucker-like muscular structure in the genital atrium, whereas $P r$. medusae is known to have muscular bundles which are almost sucker-like in the wall of the genital atrium (Dubois, 1936; Catto \& Amato, 1994) (Fig. 5J, K). At the same time, Pr. breve and $P r$. globulare (Fig. 5L) from caimans, and Proterodiplostomum ophidum Thatcher, 1963 from a snake were described without any sucker-like or muscular structures near the genital atrium (Thatcher, 1963; Catto \& Amato, 1994).
In this study, we collected Pr. longum, Pr. globulare, Pr. medusae and an immature Proterodiplostomum species. Our specimens of Pr. longum have a well-defined sucker-like muscular structure in the genital atrium, whereas our specimens of Pr. medusae and the immature Proterodiplostomum sp. had wellpronounced muscle bundles in the wall of the genital atrium, which were almost sucker-like. In contrast, our specimens of Pr. globulare lacked any sucker-like or muscular structure in the wall of the genital atrium.

Our phylogenetic analyses revealed Proterodiplostomum to be non-monophyletic. Proterodiplostomum longum (type-species), Pr. medusae and the immature Proterodiplostomum sp. formed a strongly supported clade in our analyses (Figs. 1-3). These three species have a sucker-like structure or well-defined muscle bundles in the wall of the genital atrium. In contrast, Pr. globulare, which lacks the sucker-like structure in the genital atrium, formed one of the branches in the basal polytomy within the Proterodiplostomidae in all our analyses (Figs. 1-3). Proterodiplostomum globulare also showed 5.4-6.1\% (59-67 bases) divergence in $28 \mathrm{~S}$ sequences and significant $22.1-23.7 \%$ (116-122 bases) divergence in $\operatorname{cox} 1$ sequences from other Proterodiplostomum species in our study (Supplementary Tables S1, S2).

Based on the absence of a sucker-like structure in the genital atrium of $P r$. globulare along with the strong phylogenetic evidence, we erect the genus Proteroduboisia n. g. for Pr. globulare.

\section{Proteroduboisia Tkach, Achatz \& Melo n. g.}

\section{Diagnosis}

Body bipartite; prosoma elliptic, folicaeous; opisthosoma elongate, cylindrical. Oral and ventral suckers moderately developed; holdfast organ elliptical or subspherical, with papillae on margin of median slit. Pseudosuckers absent. Pharynx moderately developed; caeca reaching near level of genital atrium. Testes 2, tandem; paraprostate relatively small; ejaculatory duct and efferent duct of paraprostate open together at apex of genital cone. Ovary pretesticular. Vitellarium extends from below or at level of ventral sucker to posterior margin of anterior testis or near posterior end of body. Metraterm opens separately from male ducts into genital atrium. Genital atrium 
subterminal with dorsal opening. In caimans. Neotropics.

Type-species: Proteroduboisia globulare (Catto \& Amato, 1994) Tkach, Achatz \& Melo n. comb. Other species: Proteroduboisia breve (Catto \& Amato, 1994) Tkach, Achatz \& Melo n. comb., Proteroduboisia ophidum (Thatcher, 1963) Tkach, Achatz \& Melo n. comb.

ZooBank registration: The Life Science Identifier (LSID) for Proteroduboisia n. g. is urn:lsid:zoobank.org:act:1BD01B4D-12B0-433C-A51ACD46E147F84F.

Etymology: The genus is named after Dr. Georges Dubois in recognition of his fundamental contributions to trematodology and particularly to our knowledge of the Proterodiplostomidae and other diplostomoideans.

Remarks

Proteroduboisia n. g. differs by $3.2-6.1 \%$ of nucleotide positions in $28 \mathrm{~S}$ sequences and $20.2-22.3 \%$ of nucleotide positions in cox 1 sequences from all other genera with available DNA sequence data (Supplementary Tables S1, S2).

Proteroduboisia $\mathrm{n}$. g. can be easily morphologically differentiated from Heterodiplostomum and Capsulodiplostomum by the lack of a muscular pouch surrounding the paraprostate in Heterodiplostomum (Fig. 5L, S) or the paraprostate, ejaculatory duct and metraterm in Capsulodiplostomum (not shown in Fig. 5 due to the very poor quality of the illustration in the original description). Although relatively small, the paraprostate of Proteroduboisia n. g. is welldefined compared to the apparent lack of the paraprostate in Mesodiplostomum and Proalarioides (Fig. 5L, T, U). The holdfast organ in Proteroduboisia n. g. occupies approximately a quarter or less of the prosoma length, whereas in Ophiodiplostomum the holdfast organ occupies approximately half of the prosoma length. Proteroduboisia n. g. can be differentiated from most other proterodiplostomid genera based on the topology of the terminal reproductive ducts. The ejaculatory duct and efferent duct of the paraprostate open side by side in Proteroduboisia $\mathrm{n}$. $\mathrm{g}$. without forming a common male efferent duct, while the metraterm opens separately. The ejaculatory duct, paraprostate and metraterm unite in different ways to form a common duct in Archaeodiplostomum, Crocodilicola, Neocrocodilicola, Polycotyle and Pseudocrocodilicola, whereas the paraprostate of Cheloniodiplostomum, Cystodiplostomum, Herpetodiplostomum, Paradiplostomum and Prolecithodiplostomum opens distinctly separately from the ejaculatory duct. In Pseudoneodiplostomum and Paraproterodiplostomum n. g. the ejaculatory duct joins the paraprostate (Fig. 5G, H). Morphological differences between Proteroduboisia n. g. and Proterodiplostomum are already discussed above.

Due to the erection of Proteroduboisia n. g. and transfer of three species into the new genus we provide an amended diagnosis of Proterodiplostomum.

\section{Proterodiplostomum Dubois, 1936}

\section{Diagnosis}

[After Niewiadomska (2002), amended.] Body distinctly bipartite; prosoma flattened, spatulate, typically much shorter than cylindrical opisthosoma. Oral sucker and ventral sucker moderately developed; holdfast organ elliptical, elongate, with papillae on margin of median slit. Pseudosuckers absent. Pharynx small or moderately developed; caeca reaching near level of genital atrium. Testes 2, tandem; anterior testis near middle of opisthosoma. Paraprostate welldeveloped, tubular, reaching close to posterior testis. Ejaculatory duct and efferent duct of the paraprostate open together at apex of genital cone. Ovary pretesticular; oötype intertesticular. Vitellarium distributed throughout prosoma and opisthosoma, anterior extent before or after ventral sucker, posterior extent reaching about level of paraprostate. Metraterm opens separately from male ducts near base of genital cone. Muscular sucker-like structure or denser musculature present in wall of genital atrium. Genital atrium with subterminal opening, on dorsal side. Excretory pore terminal. In crocodilians. Neotropics.

Type-species: Proterodiplostomum longum (Brandes, 1888).

Other species: Proterodiplostomum tumidulum Dubois, 1936, Proterodiplostomum medusae (Dubois, 1936). 


\section{Status of Pseudoneodiplostomoides}

Prior to this study, no members of the Proterodiplostomidae had been reported from Australian crocodilians. Two members of Pseudoneodiplostomoides, a previously accepted subgenus of Pseudoneodiplostomum, were described by Tubangui \& Masiluñgan (1936) and Yamaguti (1954) from saltwater crocodile Crocodylus porosus Schneider from the Philippines and Indonesia, respectively. Tubangui \& Masiluñgan (1936) originally placed their species ( $P$ u. crocodilarum) from the Philippines within the genus Neodiplostomum Railliet, 1919. Yamaguti (1954) later established the subgenus Pseudoneodiplostomoides for his newly described Pseudoneodiplostomum (Pseudoneodiplostomoides) crocodili Yamaguti, 1954 and $P u$. crocodilarum, in part based on the presence of two muscular pits in the genital atrium. Dubois (1979) listed both of these species as synonyms of Pe. siamense. We disagree with Dubois'synonymisation because of the lack of the characteristic "pits" or concave invaginations of the genital atrium wall in Pe. siamense, but their presence in the members of Yamaguti's subgenus Pseudoneodiplostomoides. Our molecular data support this notion with $1.4 \%$ (15 bases) divergence between $P e$. siamense and $\mathrm{Pu}$. crocodilarum in the $28 \mathrm{~S}$ gene and $17.7 \%$ ( 92 bases) divergence in cox 1 . Considering the substantial level of sequence divergence (Supplelmentary Tables S1, S2), the results of our phylogenetic analyses (Figs. 1-3) and the lack of the characteristic invaginations in the genital atrium of all other Pseudoneodiplostomum species, including our specimens representing four species, we restore Pseudoneodiplostomoides and elevate it to genus level. Since the only character Yamaguti (1954) used to separate $P u$. crocodili and Pu. crocodilarum was the width of the eggs, we consider $P u$. crocodili a junior synonym of $P u$. crocodilarum (Tubangui \& Masiluñgan, 1936) n. comb. which becomes the type-species of Pseudoneodiplostomoides. Yamaguti (1954) provided an adequate diagnosis of Pseudoneodiplostomoides, therefore we do not include an amended diagnosis here.

\section{Content of Pseudoneodiplostomum}

Pseudoneodiplostomum includes four currently accepted species: Pe. thomasi (type-species) and $P e$. bifurcatum from Africa, $P e$. siamense from Southeast
Asia, and Pe. groschafti from Cuba (Dubois, 1979; Moravec, 2001). Pseudoneodiplostomum thomasi was originally described by Dollfus (1935) from the intestine of the dwarf crocodile Osteolaemus tetraspis Cope collected in the French Congo. Dubois (1948) examined specimens collected from the intestine of the West African slender-snouted crocodile Mecistops cataphractus (Cuvier) collected in Gabon that were previously identified as Pe. thomasi. Based on these specimens, Dubois (1948) established the subspecies Pe. thomasi gabonicum Dubois, 1948, which differed from the nominal subspecies Pe. thomasi thomasi by the greater opisthosoma:prosoma ratio, narrower body, as well as the smaller ventral sucker, holdfast organ, ovary and testes.

Our specimens of Pe. thomasi thomasi and Pe. thomasi gabonicum differ by $0.2 \%$ of $28 \mathrm{~S}$ sequences. For comparison, 28S sequences of Pe. bifurcatum and $P e$. thomasi were identical despite the two species having very distinct morphologies. Based on the morphological and genetic differences we elevate Pe. thomasi gabonicum to species level as Pe. gabonicum Dubois, 1948 n. nom.

\section{Notes on other genera}

Crocodilicola pseudostoma was originally described from Al. mississippiensis collected in South Carolina, USA (Willemoes-Suhm, 1870) and later reported from the same host in several locations in the USA, as well as from Morelet's crocodile Co. moreletii in Mexico (Tellez, 2014). Our analyses of $28 \mathrm{~S}$ and cox 1 included sequences of $\mathrm{Cr}$. pseudostoma from GenBank published by Hernández-Mena et al. (2017). These sequences came from a metacercaria collected from fish in Catemaco Lake, Veracruz, southern Mexico, thousands of kilometers from the type-territory of $\mathrm{Cr}$. pseudostoma or the nearest current area populated by alligators. In our phylogenetic analyses, these sequences formed strongly supported clades with proterodiplostomids from caimans collected in Brazil (Figs. 1-3). The distribution of Co. moreletii overlaps with that of caimans, but not with the range of the American alligator. All proterodiplostomids from Al. mississippiensis included in our analyses, formed a strongly supported monophyletic group and all other genera of proterodiplostomids parasitising crocodilians showed close association with a single genus of their definitive hosts (Fig. 2). 
The combination of the definitive host distribution patterns and the phylogenetic placement of $\mathrm{Cr}$. pseudostoma sequences from GenBank suggests that the identification of these metacercariae should be considered with caution. Although Cr. pseudostoma was reported from Co. moreletii in Mexico (Dubois, 1953; Thatcher, 1964), we believe these reports were a result of misidentification due to the poor condition of the specimens. We examined specimens of $\mathrm{Cr}$. pseudostoma from Co. moreletii in Mexico deposited in the HWML (see Materials and methods). Despite the very poor state of the specimens on slides it was evident that they do not belong to Crocodilicola. The ejaculatory duct in these specimens joins the paraprostate near its proximal end and the metraterm clearly does not join the merged ejaculatory duct and paraprostate. In $\mathrm{Cr}$. pseudostoma the metraterm, ejaculatory duct and paraprostate merge to form a common duct. Most likely, these specimens represent a new species; however, their state does not allow for a quality description. Sequencing of an adult stage of Cr. pseudostoma from alligators as well as of proterodiplostomids from Co. moreletii in the future will eventually support or reject the identification of the metacercariae in Hernández-Mena et al. (2017). We anticipate that it will turn out to be a new genus, possibly shared between caimans and crocodiles in the Neotropics.

Cystodiplostomum hollyi is the type-species of the monotypic genus Cystodiplostomum. Our unidentified Cystodiplostomum sp. formed a 100\% supported clade with $C y$. hollyi in both $28 \mathrm{~S}$ and $\operatorname{cox} 1$ analyses. It most likely represents a second member of the genus, but our only specimen was used for DNA extraction. Due to the relatively high level of genetic divergence, it is also possible that our specimen represents another genus not available for our analysis, such as Prolecithodiplostomum, in which the topology of terminal reproductive ducts is identical to that of Cystodiplostomum (Fig. 5M).

Unlike other proterodiplostomid taxa included in our study, adult Heterodiplostomum are parasites of the intestines of snakes in the Neotropics and are known to use amphibians as second intermediate hosts (Niewiadomska, 2002; Queiroz et al., 2020). At present, Heterodiplostomum includes two species: He. lanceolatum and Heterodiplostomum helicopsis
Mañé-Garzón \& Alonso, 1976. Ribosomal sequences from metacercaria of He. lanceolatum collected from pointed belly frogs Leptodactylus podicipinus (Cope) in Brazil were recently published (Queiroz et al., 2020) and differ from our sequences of Heterodiplostomum lanceolatum by $0.2 \%$ (2 nucleotides). No cox 1 sequences are available for the previously published He. lanceolatum isolate. Heterodiplostomum lanceolatum has been described with caeca that terminate anterior to the copulatory bursa and vitellarium that do not extend anterior passed the holdfast organ; whereas the caeca of $\mathrm{He}$. helicopsis terminate near the distal extremity of the opisthosoma and the vitellarium extend anteriorly to near the level of the caecal fork (Dubois, 1936; MañéGarzón \& Alonso, 1976). Whereas our specimens of Heterodiplostomum from L. chaquensis and E. poecilogyrus were immature, their morphology corresponded to the description of He. lanceolatum (i.e. caeca terminate immediately anterior to the copulatory bursa and vitellarium does not pass the level of the holdfast organ). We suspect that the difference in the $28 \mathrm{~S}$ gene sequences may be indicative of the presence of a cryptic species. None of the remaining proterodiplostomids included in this study had more than a single variable nucleotide site within a species and $P e$. bifurcatum and Pe. thomasi had no differences in their 28S sequences (Supplementary Table S1). However, future studies will have to include sequences from adult Heterodiplostomum specimens along with sequences of faster mutating genes (e.g. cox 1 ) to properly test for the presence of cryptic species within this genus.

As a result of the present revision of several proterodiplostomid taxa and abandonment of the subfamilies within the Proterodiplostomidae, the family now includes 21 genera. We expect additional changes in the system of this family as our knowledge of proterodiplostomid diversity and morphology, as well as greater sequencing coverage, will continue to improve with further studies. Nevertheless, we consider it useful to provide a key to the identification of the currently recognised proterodiplostomid genera. Although we do not believe that hosts or geographical distribution should be used as characters in the identification, we provide this information in the key for convenience. 
Key to the genera of the Proterodiplostomidae

1a Paraprostate absent .......................... 2

1b Paraprostate present .......................... 3

2a Ejaculatory duct and metraterm merge to form hermaphroditic duct near apex of genital cone. Hermaphroditic duct not enclosed in a muscular pouch. Pseudosuckers absent. In crocodilians. Neotropics Mesodiplostomum

2b Ejaculatory duct and metraterm merge to form hermaphroditic duct enclosed in a muscular pouch. Pseudosuckers present. In snakes. Palaeartic and Orient

Proalarioides

3a Paraprostate surrounded by muscular pouch. Paraprostate duct eversible. Ejaculatory duct and metraterm open side by side. In snakes. Neotropics ................. Heterodiplostomum

3b Paraprostate not surrounded by muscular pouch or all terminal ducts of reproductive system enclosed in single muscular pouch ........... 4

4a Entire paraprostate, ejaculatory duct, and metraterm enclosed in muscular pouch. Ejaculatory duct and metraterm open separately. In crocodilians. India

.Capsulodiplostomum

4b Paraprostate, ejaculatory duct, and metraterm not enclosed in muscular pouch. Ejaculatory duct and metraterm open separately or have a common opening ........................... 5

5a Vitellarium confined to opisthosoma. In crocodilians. Neotropics

Massoprostatum

$5 \mathrm{~b} \quad$ Vitellarium distributed differently ........... 6

6a Holdfast organ relatively massive, typically occupying approximately half of prosoma ...

$6 \mathrm{~b}$ Holdfast organ not as massive, typically occupying approximately $25-30 \%$ of prosoma

7a Ejaculatory duct joins distal part of paraprostate. Two muscular pits, occasionally sucker-like, present in wall of genital atrium. In crocodilians. Australasia

\section{Pseudoneodiplostomoides}

$7 \mathrm{~b}$ Ejaculatory duct and paraprostate do not join/ unite. Muscular pits in wall of genital atrium absent. In snakes. Neotropics

Ophiodiplostomum 8a Metraterm, ejaculatory duct and paraprostate join to form a common duct or all three share common opening .......................... 9

8 b Metraterm, ejaculatory duct and paraprostate do not form common duct. Ejaculatory duct and paraprostate or ejaculatory duct and metraterm may join or share common opening ........ 13

9a Opisthosoma with longitudinal row of suckerlike structures on dorsal side. In crocodilians. Nearctic Polycotyle

9b Opisthosoma without dorsal sucker-like structures ...................................... 10

10a Terminal part of paraprostate, ejaculatory duct, and metraterm enclosed in muscular pouch

10b Paraprostate, ejaculatory duct, and metraterm not enclosed in muscular pouch .............12

11a Ejaculatory duct typically joins paraprostate near its midpoint. In crocodilians. Nearctic Pseudocrocodilicola

11b Ejaculatory duct joins paraprostate near its proximal end. In crocodilians. Nearctic. Neocrocodilicola $\mathrm{n} . \mathrm{g}$.

12a Vitelline follicles confined to area around holdfast organ. Separation between prosoma and opisthosoma indistinct. In crocodilians. Nearctic and Neotropics

Crocodilicola

12b Vitelline follicles distributed in both prosoma and opisthosoma, extending well beyond area around holdfast organ. Separation between prosoma and opisthosoma distinct. In crocodilians. Nearctic ........... Archaeodiplostomum

13a Paraprostate opens separately from ejaculatory duct and metraterm. Ejaculatory duct and metraterm may join or share common opening 14

13b Metraterm opens separately from ejaculatory duct and paraprostate. Ejaculatory duct and paraprostate may join or share common opening

14a Genital cone present $\ldots \ldots \ldots \ldots \ldots \ldots$

14b Genital cone absent ...................... 17

15a Genital cone massive, equal to about $1 / 4$ of total body length. In crocodilians. Neotropics ...... Paradiplostomum

15b Genital cone much smaller, not more than $1 / 8$ of total body length ......................... 16 
16a Holdfast organ with papillae. In crocodilians. Neotropics ................ Herpetodiplostomum

16b Holdfast organ without papillae. In chelonians. Neotropics .............. Cheloniodiplostomum

17a Thick-walled, sucker-like dorsal invagination of body present near midpoint of opisthosoma or slightly more posterior. In crocodilians. Neotropics .................. Cystodiplostomum

17b No thick-walled, sucker-like dorsal invagination of body present. In crocodilians. Neotropics ......................... Prolecithodiplostomum

18a Sucker-like muscular structure (well-developed or concentrated muscle bundles) in the wall of the genital atrium present. In crocodilians. Neotropics ................. Proterodiplostomum

18b Genital atrium without sucker-like structure 19

19a Ejaculatory duct does not join paraprostate. Ejaculatory duct and paraprostate share common opening. In crocodilians and snakes. Neotropics ............... Proteroduboisia n. g.

19b Ejaculatory duct joins paraprostate .......... 20

20a Ejaculatory duct joins paraprostate near its distal end. Paraprostate well-developed. In crocodilians. Nearctic

Paraproterodiplostomum n. g.

20b Ejaculatory duct joins proximal half of paraprostate. Paraprostate weakly developed. In crocodilians. Africa, Australasia and Neotropics Pseudoneodiplostomum

\section{Host and geographical associations}

The Proterodiplostomidae clearly is a very old evolutionary lineage of digeneans parasitising an ancient group of hosts that already existed and strongly radiated before the separation and subsequent drift of the current continents. In a series of works, Brooks and co-authors (Brooks, 1979; Brooks \& O'Grady, 1989; Brooks et al., 1992) presented morphology-based phylogenies of the Proterodiplostomidae (along with some other digenean groups parasitic in crocodilians) and analysed their historical biogeography as well as host associations. These authors emphasised that the history of proterodiplostomid associations with their crocodilian hosts extended deep into the geological and evolutionary past and was affected by major global geological events such as tectonic plate movement and accompanying radiation among and within the crocodilian lineages.

Our phylogenetic analyses supported some of the conclusions drawn in these publications, e.g. regarding the monophyly of the proterodiplostomids parasitising alligators. The arrangement of the remaining taxa showed, however, a substantial disagreement. Although our 28S tree was not fully resolved (Fig. 2) it provides some new insights into the historical biogeography and host associations of the Proterodiplostomidae. This is particularly interesting considering the recent advances in the phylogenetics of crocodilians and discovery of cryptic species based on both morphological and molecular criteria (e.g. Brochu, 1997, 2003; Bittencourt et al., 2019; Brochu \& Sumrall, 2020; Roberto et al., 2020). Molecular data also suggested a relatively recent radiation and active speciation of the true crocodiles (Oaks, 2011).

Although morphology based phylogenetic hypotheses incorporating both the extant and extinct species suggested that gharials (Gavialidae Adams) represent the most basal lineage of extant crocodilians (Brochu, 1997, 2003), the molecular phylogenies (Oaks, 2011) strongly suggested that the Alligatoridae Gray is the basal extant group. Although our 28S phylogeny was not completely resolved, the interrelationships between proterodiplostomids correspond well to the phylogenetic affinities among crocodilians (Figs. 2, 7).

According to our data, the proterodiplostomids of alligatorids are not monophyletic (but those parasitic in American alligators are) because the genera associated with caimans are found in three different clades. This tree topology allows us to hypothesise that the proterodiplostomids parasitic in crocodilians have first evolved and radiated into several lineages in the ancestors of modern caimans yet in Pangea. Some of these lineages were either inherited by alligators and then true crocodiles in the process of crocodilian radiation or passed as a result of subsequent host switching events. This hypothesis corresponds with at least some of the previously suggested schemes of the biogeographic relationships among crocodilians (Sill, 1968; Brooks, 1979). The evidence of at least one genus (Pseudoneodiplostomum) shared between members of the genus Crocodylus in Africa and Australia (and Asia according to published morphology-only data) fits well the hypothesis of relatively 


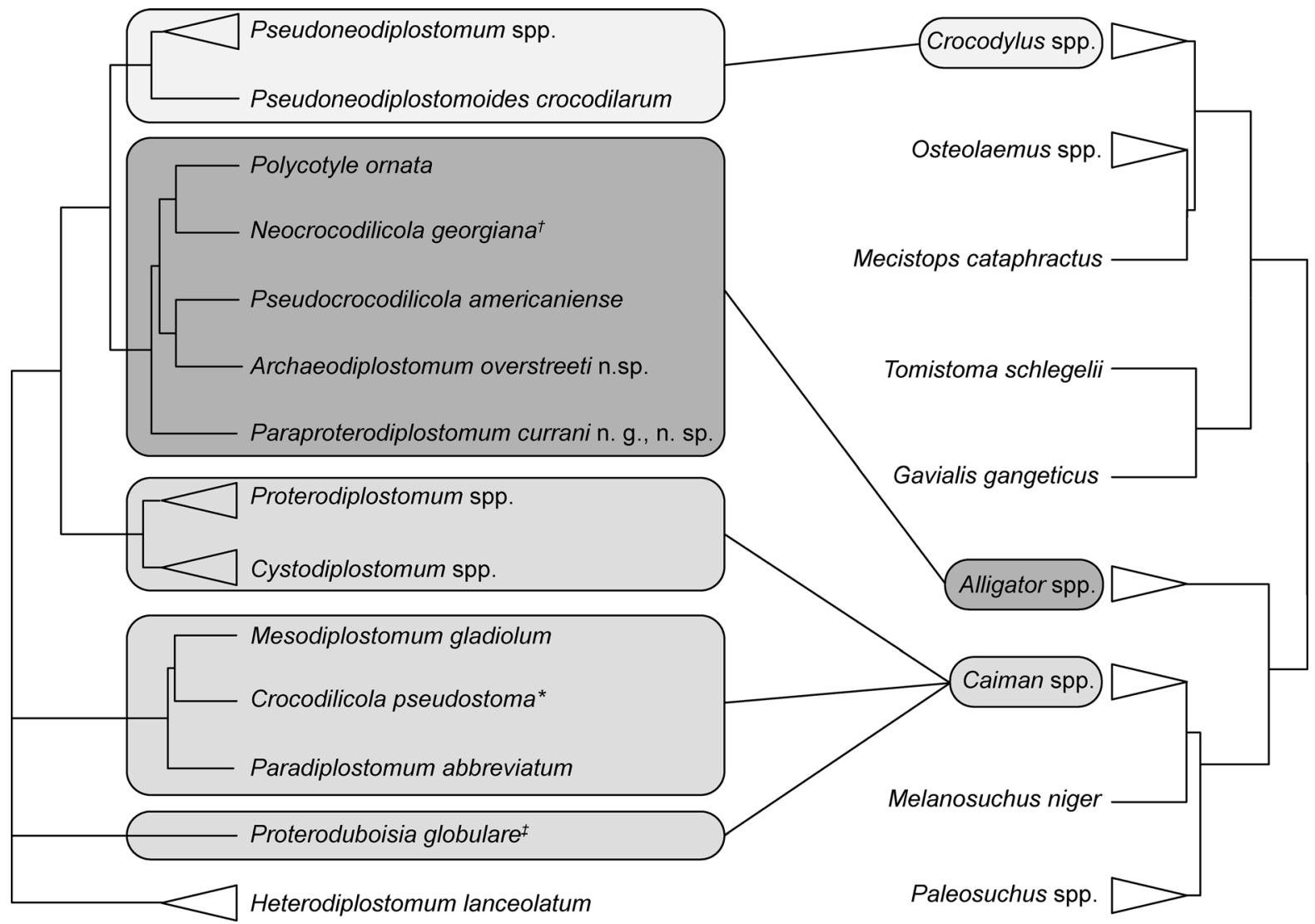

Fig. 7 Phylogenetic tree of the Proterodiplostomidae from the present study and the molecular phylogenetic tree of the Crocodilia (modified from Oaks, 2011) showing host associations between currently sequenced proterodiplostomids and extant crocodilian linages. Phylogenetic trees are presented as rectangular cladograms for convenience. Connecting lines and identical shades of grey color indicate host associations

recent active radiation of Crocodylus (see Oaks, 2011; Figs. 2, 7). The close relationships between clades uniting parasites of Alligator and Crocodylus suggest that as true crocodiles radiated they likely received their original proterodiplostomids from ancestors of modern alligators. It is difficult to speculate, however, where this could have happened geographically due to the broad distribution of both crocodilian lineages in the past.

Despite the paraphyly shown by the proterodiplostomids parasitic in caimans, all sub-clades in our tree (Figs. 2, 7) demonstrated strong associations between genera of proterodiplostomids and crocodilians. Proterodiplostomids from Alligator and Crocodylus formed well-supported monophyletic clades despite the high level of morphological diversification among members of each clade. The only deviation from the strict specificity to host genera in monophyletic clades in the $28 \mathrm{~S}$ tree is the position of Cr. pseudostoma (GenBank: MF398328) together with Paradiplostomum and Mesodiplostomum, parasites of caimans (Fig. 2). As explained above, we believe that the sequences deposited in GenBank as Cr. pseudostoma were obtained from erroneously identified metacercariae.

\section{Missing taxa and future prospects}

Despite our extensive sampling effort and the broad representation of proterodiplostomid taxa in the resulting dataset, some critically important taxa and sequences from them are still missing. There are several crocodilian species in Asia, Africa, South and 
Central America that have not been examined for proterodiplostomids at all. Some of them are endemic to a single island or a limited geographical area and therefore may have endemic parasite faunas. On the other hand, some crocodilians, including different species of caimans, are known as hosts of a diverse proterodiplostomid fauna, which has not been a subject of molecular systematic and phylogenetic analyses.

Some of the gaps are, however, more glaring than others. Probably the biggest gap in the available data is the lack of sequences from any proterodiplostomids parasitising gharials, which were repeatedly considered the basal group of extant crocodilians in morphology-based analyses. In addition, the distribution area of gharials lies within the overall distribution of the genus Crocodylus and overlaps with the current or recent historical distribution of the mugger crocodile Crocodylus palustris (Lesson) and Co. porosus. Equally missing and extremely interesting are proterodiplostomids from the Chinese alligator Alligator sinensis Fauvel, now critically endangered and on the brink of extinction. Therefore, only fixed museum specimens may potentially be a source of parasite samples. Other crucial hosts are the American crocodile Crocodylus acutus Cuvier, Orinoco crocodile Crocodylus intermedius Graves, and Co. moreletii whose geographic ranges overlap with the distribution areas of the American alligator and several species of caimans. Obtaining sequence data from proterodiplostomids parasitic in these hosts may potentially answer a variety of enticing questions regarding their evolutionary origin as well as the extent of physiological vs ecological specificity to their hosts. In addition to proterodiplostomids from crocodilian hosts, several known taxa of these digeneans parasitic in other hosts, such as snakes and turtles, are also awaiting sequencing and inclusion in future phylogenetic analyses.

Nevertheless, despite the lack of some important proterodiplostomids taxa in our analysis we believe that the views on their interrelationships and systematics presented here are well supported. Denser taxonomic sampling from a greater diversity of hosts and additional geographic areas should provide a solid background for a better understanding of the Proterodiplostomidae and their evolution and address the remaining unanswered questions presented in this study.
Acknowledgements We are grateful to Dr Danny Govender (SANParks, South Africa), Professor Joop Boomker (University of Pretoria, South Africa) as well as Mr Frans R. Masubelle and $\mathrm{Mr}$ Daniel M. Chipana (ARC-Onderstepoort Veterinary Institute, South Africa) for facilitating and assisting in parasite collections from Nile crocodiles. We are thankful to Dr Joao B. Pinho (Laboratório de Ecologia de Aves, Federal University of Mato Grosso, Cuiabá, Brazil) for his invaluable assistance with collecting specimens in Pantanal. We also sincerely thank Dr Nguyen Van Ha (Institute of Ecology and Biological Resources, Hanoi, Vietnam) for his help with collecting specimens in Vietnam. We are indebted to Dr Stephen Bullard and his graduate students Jackson Roberts and Micah Warren (all at Auburn University) who provided specimens of Proterodiplostomum longum collected in Peru. We are indebted to Dr Robin Overstreet (Gulf Coast Research Laboratory, University of Southern Mississippi, Ocean Springs, USA) for help with logistics and providing access to his laboratory during fieldwork in Mississippi. We thank Dr Gabor Racz (HWML, University of Nebraska at Lincoln, USA), who graciously helped us with the study of specimens of Crocodilicola pseudostoma deposited in HWML by offering a remote screen sharing microscope session during the COVID-19 pandemic. Collecting and processing of the specimens from Southeast Asia, North America and Europe were supported in part by grant R15AI092622 from the National Institutes of Health, USA and grant DEB1021431 from the National Science Foundation to V. V. Tkach, NSF-DEB grants 1051106 and 1112729 to Stephen Bullard, and the Joe K. Neel Memorial Award and W. H. Wheeler Award from the Department of Biology, University of North Dakota and an AMCOP Student Research Grant from the Annual Midwestern Conference of Parasitologists to T. J. Achatz. This study was also supported by the Conselho Nacional de Desenvolvimento Científico e Tecnológico (CNPq) (grant n. 431809/2018-6) which provided the research fellowship to FTVM (process n. 304955/2018-3). We are thankful to ICMBio/SISBIO that kindly provided a collecting permit to Pantanal, Brazil (license permission SISBIO: 53527-4). Sampling in South Africa by AH was partly supported by the VLIR-IUC (Vlaamse Interuniversitaire Raad - University Development Cooperation) Funding Programme (Belgium) and the South African Research Chairs Initiative (SARChI) of the Department of Science and Innovation (DSI) and National Research Foundation (NRF) of South Africa (Grant No. 101054).

\section{Compliance with ethical standards}

Conflicts of interest The authors declare that they have no conflicts of interest.

Ethical approval All applicable institutional, national and international guidelines for the care and use of animals were followed. 


\section{References}

Achatz, T. J., Curran, S. S., Patitucci, K. F., Fecchio, A., \& Tkach, V. V. (2019a). Phylogenetic affinities of Uvulifer spp. (Digenea: Diplostomidae) in the Americas with description of two new species from Peruvian Amazon. Journal of Parasitology, 105, 704-717.

Achatz, T. J., Dmytrieva, I., Kuzmin, Y., \& Tkach, V. V. (2019b). Phylogenetic position of Codonocephalus (Digenea, Diplostomoidea), an unusual diplostomid with progenetic metacercariae. Journal of Parasitology, 105, 821-826.

Achatz, T. J., Pulis, E. E., Fecchio, A., Schlosser, I. J., \& Tkach, V. V. (2019c). Phylogenetic relationships, expanded diversity and distribution of Crassiphiala (Digenea, Diplostomidae), agents of black spot disease in fish. Parasitology Research, 118, 2781-2787.

Achatz, T. J., Pulis, E. E., Junker, K., Binh, T. T., Snyder, S. D., \& Tkach, V. V. (2019d). Molecular phylogeny of the Cyathocotylidae (Digenea, Diplostomoidea) necessitates systematic changes and reveals a history of host and environment switches. Zoologica Scripta, 48, 545-556.

Achatz, T. J., Pulis, E. E., González-Acuña, D., \& Tkach, V. V. (2020). Phylogenetic relationships of Cardiocephaloides spp. (Digenea, Diplostomoidea) and the genetic characterization of Cardiocephaloides physalis from Magellanic Penguin, Spheniscus magellanicus, in Chile. Acta Parasitologica, 65, 525-534.

Bittencourt, P. S., Campos, Z., Muniz, F. L., Marioni, B., Souza, B. C., Silveira, R. A., et al. (2019). Evidence of cryptic lineages within a small South American crocodilian: the Schneider's dwarf caiman Paleosuchus trigonatus (Alligatoridae: Caimaninae). PeerJ, 7, e6580.

Blasco-Costa, I., \& Locke, S. A. (2017). Life history, systematics and evolution of the Diplostomoidea Poirier, 1886: progress, promises and challenges emerging from molecular studies. Advances in Parasitology, 98, 167-225.

Brochu, C. A. (1997). Morphology, fossils, divergence timing, and the phylogenetic relationships of Gavialis. Systematic Biology, 46, 479-522.

Brochu, C. A. (2003). Phylogenetic approaches toward crocodylian history. Annual Review of Earth and Planetary Sciences, 31, 357-397.

Brochu, C. A., \& Sumrall, C. D. (2020). Modern cryptic species and crocodylian diversity in the fossil record. Zoological Journal of the Linnean Society, 189, 700-711.

Brooks, D. R. (1979). Testing hypotheses of evolutionary relationships among parasites: the digeneans of crocodilians. American Zoologist, 19, 1225-1238.

Brooks, D. R., Catto, J. B., \& Amato, J. F. R. (1992). A new phylogenetic classification of the genera of the Proterodiplostomidae Dubois, 1936 (Digenea: Strigeiformes). Proceedings of the Biological Society of Washington, 105, 143-147.

Brooks, D. R., \& O'Grady, R. T. (1989). Crocodilians and their helminth parasites: Macroevolutionary considerations. American Zoologist, 29, 873-883.

Byrd, E. E., \& Reiber, R. J. (1942). Strigeid trematodes of the alligator, with remarks on the prostate gland and terminal portions of the genital ducts. Journal of Parasitology, 28, 51-73.

Catto, J. B., \& Amato, J. F. R. (1994). Proterodiplostome parasites (Digenea, Proterodiplostomidae) of the caiman, Caiman crocodilus yacare (Reptilia, Crocodylia) in the Pantanal Mato-Grossense, Brazil, with the description of two new species. Memorias Instituto Oswaldo Cruz, 89, 539-551.

Derycke, S., Remerie, T., Vierstraete, A., Backeljau, T., Vanfleteren, J., Vincx, M., et al. (2005). Mitochondrial DNA variation and cryptic speciation within the free-living marine nematode Pellioditis marina. Marine Ecology Progress Series, 300, 91-103.

Dollfus, R. P. (1935). Sur Crocodilicola et autres hemistomes de crocodiliens. Archives du Muséum d'Histoire Naturelle, 12, 637-646.

Dubois, G. (1936). Les diplostomes de reptiles (Trematoda: Proterodiplostomidae nov. fam.) du Musée de Vienne. Bulletin de la Société Neuchâteloise des Sciences Naturelles, 61, 5-80.

Dubois, G. (1948). Sur trois Diplostomes de Crocodiliens (Trematoda: Strigeida). Annales de Parasitologie, 23, $5-13$.

Dubois, G. (1951). Nouvelle clé de détermination des groupes systématiques et des genres de Strigeida Poche (Trematoda). Revue Suisse de Zoologie, 58, 639-691.

Dubois, G. (1953). Systématique des Strigeida: Complément de la monographie. Memoires de la Societe Neuchâteloise des Sciences Naturelles, 8, 1-141.

Dubois, G. (1979). Révision et nouvelle clé de déterminations des Diplostomes de Reptiles. Bulletin de la Société Neuchâteloise des Sciences Naturelles, 102, 39-48.

Hernández-Mena, D. I., García-Varela, M., \& Pérez-Ponce de León, G. (2017). Filling the gaps in the classification of the Digenea Carus, 1863: systematic position of the Proterodiplostomidae Dubois, 1936 within the superfamily Diplostomoidea Poirier, 1886, inferred from nuclear and mitochondrial DNA sequences. Systematic Parasitology, 94, 833-848.

ICZN (2012). International Commission on Zoological Nomenclature: Amendment of articles 8, 9, 10, 21 and 78 of the International Code of Zoological Nomenclature to expand and refine methods of publication. Bulletin of Zoological Nomenclature, 69, 161-169.

Kudlai, O., Kostadinova, A., Pulis, E. E., \& Tkach, V. V. (2015). A new species of Drepanocephalus Dietz, 1909 (Digenea: Echinostomatidae) from the double-crested cormorant Phalacrocorax auritus (Lesson) (Aves: Phalacrocoracidae) in North America. Systematic Parasitology, 90, 221-230.

Kumar, S., Stecher, G., \& Tamura, K. (2016). MEGA7: Molecular Evolutionary Genetics Analysis version 7.0 for bigger datasets. Molecular Biology and Evolution, 33, 1870-1874.

Locke, S. A., Van Dam, A. R., Caffara, M., Pinto, H. A., LópezHernández, D., \& Blanar, C. A. (2018). Validity of the Diplostomoidea and Diplostomida (Digenea, Platyhelminthes) upheld in phylogenomic analysis. International Journal for Parasitology, 48, 1043-1059.

Lockyer, A. E., Olson, P. D., Østergaard, P., Rollinson, D., Johnston, D. A., Attwood, S. W., et al. (2003). The 
phylogeny of the Schistosomatidae based on three genes with emphasis on the interrelationships of Schistosoma Weinland, 1858. Parasitology, 126, 203-224.

Lutz, H. L., Tkach, V. V., \& Weckstein, J. D. (2017). Methods for specimen-based studies of avian symbionts. In: Webster, M. (Ed.), The Role of Collections in Ornithology: The Extended Specimen. Studies in Avian Biology. Florida: CRC Press. pp. 127-183.

Mañé-Garzón, F., \& Alonso, A. (1976). Em nueva espécie de Digenea Strigeoidea. Heterodiplostomum helicopsis $\mathrm{n}$. sp. del intestino de la culebra de água Helicops carinicaudus (Wied, 1825). Revista de Biologia del Uruguay, 4, 85-91.

Miller, T. L., \& Cribb, T. H. (2008). Family Cryptogonimidae Ward, 1917. In: Bray, R. A., Gibson, D. I. \& Jones, A. (Eds), Keys to the Trematoda, Volume 3. Wallingford: CABI Publishing and The Natural History Museum, pp. 52-112.

Moravec, F. (2001). Some helminth parasites from Morelet's crocodile, Crocodylus moreletii, from Yucatan, Mexico. Folia Parasitologica, 48, 47-62.

Moszczynska, A., Locke, S. A., McLaughlin, J. D., Marcogliese, D. J., \& Crease, T. J. (2009). Development of primers for the mitochondrial cytochrome $c$ oxidase I gene in digenetic trematodes (Platyhelminthes) illustrates the challenge of barcoding parasitic helminths. Molecular Ecology Resources, 9, 75-82.

Niewiadomska, K. (2002). Family Proterodiplostomidae Dubois, 1936. In: Gibson, D. I., Jones, A. \& Bray, R. A. (Eds), Keys to the Trematoda, Volume 1. Wallingford: CABI Publishing and The Natural History Museum, pp. 215-229.

Oaks, J. R. (2011). A time-calibrated species tree of Crocodylia reveals a recent radiation of the true crocodiles. Evolution, 65, 3285-3297.

Queiroz, M., López-Hernández, D., Locke, S., Pinto, H., \& Anjos, L. (2020). Metacercariae of Heterodiplostomum lanceolatum (Trematoda: Proterodiplostomidae) found in Leptodactylus podicipinus (Anura: Leptodactylidae) from Brazil: A morphological, molecular and ecological study. Journal of Helminthology, 94, E66.

Roberto, I. J., Bittencourt, P. S., Muniz, F. L., HernándezRangel, S. M., Nóbrega, Y. C., Ávila, R. W., et al. (2020). Unexpected but unsurprising lineage diversity within the most widespread Neotropical crocodilian genus Caiman (Crocodylia, Alligatoridae). Systematics and Biodiversity, 18, 377-395.

Ronquist, F., \& Huelsenbeck, J. P. (2003). MRBAYES 3: Bayesian phylogenetic inference under mixed models. Bioinformatics, 19, 1572-1574.
Sill, W. D. (1968). The zoogeography of the Crocodilia. Copeia, 1968, 76-88.

Sudarikov, V. E. (1960). [Order Strigeata La Rue, 1926. Part 3. Superfamily Diplostomatoidea Nicoll, 1937. Families Alariidae Tubangui, 1922 and Bolbocephaloidea Strand, 1935. Superfamily Proterodiplostomatoidea Sudarikov, 1960]. In: Skrjabin, K. I. (Ed.), [Trematodes of animals and man]. Osnovy Trematodologii, 18, 451-694 (In Russian).

Tellez, M. (2014). A Checklist of Host-Parasite Interactions of the Order Crocodylia (pp. 1-376). Berkeley: University of California Press.

Thatcher, V. E. (1963). Studies on the trematodes of the Mexican indigo snake (Drymarchon corais melanurus) with descriptions of two new species. Transactions of the American Microscopical Society, 82, 371-380.

Thatcher, V. E. (1964). Estudios sobre los tremátodos de reptiles de Tabasco, México: lista de huéspedes y sus parásitos. Anales de la Escuela Nacional de Ciencias Biológicas, 13, 91-96.

Tkach, V. V., Achatz, T. J., Hildebrand, J., \& Greiman, S. E. (2018). Convoluted history and confusing morphology: molecular phylogenetic analysis of dicrocoeliids reveals true systematic position of the Anenterotrematidae Yamaguti, 1958 (Platyhelminthes, Digenea). Parasitology International, 67, 501-508.

Tkach, V. V., Kudlai, O., \& Kostadinova, A. (2016). Molecular phylogeny and systematics of the Echinostomatoidea Looss, 1899 (Platyhelminthes: Digenea). International Journal for Parasitology, 46, 171-185.

Tkach, V. V., Littlewood, D. T. J., Olson, P. D., Kinsella, J. M., \& Swiderski, Z. (2003). Molecular phylogenetic analysis of the Microphalloidea Ward, 1901 (Trematoda: Digenea). Systematic Parasitology, 56, 1-15.

Tkach, V. V., \& Pawlowski, J. (1999). A new method of DNA extraction from the ethanol-fixed parasitic worms. Acta Parasitologica, 44, 147-148.

Tubangui, M. A., \& Masiluñgan, V. (1936). Trematode parasites of Philippine vertebrates VIII. Flukes from a cobra and a crocodile. Philippines Journal of Science, 60, 255-266.

Willemoes-Suhm, R. V. (1870). Ueber einige Trematoden und Nemathelminthen. Zeitschrift für Wissenschaftliche Zoologie, 21, 175-203.

Yamaguti, S. (1954). Parasitic worms mainly from Celebes. Part 4. Trematodes of reptiles and birds. Acta Medica Okayama, 8, 329-340.

Publisher's Note Springer Nature remains neutral with regard to jurisdictional claims in published maps and institutional affiliations. 